\title{
Peer Effects on the United States Supreme Court
}

\author{
Richard Holden, Michael Keane and Matthew Lilley*
}

August 10, 2020

\begin{abstract}
Using data on essentially every US Supreme Court decision since 1946, we estimate a model of peer effects on the Court. We consider both the impact of justice ideology and justice votes on the votes of their peers. To identify these peer effects we use two instruments that generate plausibly exogenous variation in the peer group itself, or in the votes of peers. The first instrument utilizes the fact that the composition of the Court varies from case to case due to recusals or absences for health reasons. The second utilizes the fact that many justices previously sat on Federal Circuit Courts. Those who served on the Circuit Courts for short (long) periods of time are empirically much more (less) likely to affirm decisions from their "home" court. We find large peer effects. Replacing a single justice with one who votes in a conservative direction 10 percentage points more frequently increases the probability that each other justice votes conservative by 1.6 percentage points. Further, a 10\% increase in the probability that a given justice votes conservative leads to a 1.1 percentage point increase in the probability that each other justice votes conservative. This indirect effect increases the share of cases with a conservative outcome by 3.6 percentage points (excluding the direct effect of the new justice). In general, we find indirect effects are large relative to the direct mechanical effect of a justice's own vote.
\end{abstract}

*Holden: UNSW Business School, email: richard.holden@unsw.edu.au. Keane: UNSW Business School. Lilley: Harvard University Department of Economics, email: matthewlilley@fas.harvard.edu. We are grateful to Rosalind Dixon, John Friedman, Christine Jolls, Christopher Malloy, Emily Oster, Richard Posner, Jesse Shapiro, Andrei Shleifer, and Justin Wolfers for helpful discussions, and to seminar participants at Harvard, Harvard Law School and MIT. 


\section{Introduction}

Economists have long been interested in the impact of one's social, educational, and workplace environment-and the characteristics of other agents in that environment-on one's own behavior and outcomes. ${ }^{1}$ The presence of positive spillovers, or peer effects, in such settings would suggest a range of policy interventions that could improve educational and labor-market outcomes. More generally, peer effects may be an important determinant of outcomes in many social settings. However, the problem of statistically identifying peer effects is formidable.

As discussions in Manski (2000) and Moffitt (2001) make clear, plausible identification of peer effects requires (i) a clear definition of the peer group itself, (ii) exogenous variation in the behavior of peers (with the peer group held fixed or at least randomly assigned) and/or (iii) exogenous variation in the peer group itself (e.g., random assignment). Peers are often to some degree chosen, and thus in many contexts it is very difficult to find plausibly exogenous variation in the peer group. ${ }^{2}$ Similarly, without exogenous variation in the peer group, it becomes very difficult to find interventions that exogenously shift the behavior of one or more peers while having no direct effect on other members and holding peer group composition fixed.

The Supreme Court of the United States is a pertinent example of a context where peer effects may be of first order importance. The Court issues decisions on important political, social and constitutional questions. Accordingly the question of how the composition of the Court, and the interaction of its members, affect justices' individual votes and the majority decisions of the Court, is of intrinsic interest. Furthermore, the existence and magnitude of peer effects are important for understanding the cumulative effects of judicial appointments. In particular, the indirect effect of a new justice through the votes of existing justices may be large relative to the direct effect of their own vote. If peer effects are positive, this amplifies the stakes of judicial appointments. ${ }^{3}$ This, in turn, speaks to the characteristics and design of legal institutions.

\footnotetext{
${ }^{1}$ In the context of education, the concept of peer effects dates to at least the "Coleman Report" (Coleman et al. (1966)).

${ }^{2}$ Manski (1993) has particularly stressed the Reflection Problem-as people tend to chose peers who resemble themselves, there is typically a mechanical link between the characteristics of individuals and those of their peer group. This creates a great risk of falsely inferring that peer behavior affects own behavior, even if the causality actually runs the other way. See Manski (1993) and Manski (2000).

${ }^{3}$ Given peer effects, the ideal appointment may not simply be the one that shifts the median justice closest to the view of the President. In general, the exact functional form by which peer effects operate may alter the optimal strategy of an administration in nominating justices. But as we restrict our attention to linear-in-means peer effects for tractability, we do not investigate this possibility, but note it as an avenue for future exploration.
} 
Peer effects on the Supreme Court may operate through various channels. Perhaps most obvious are effects via persuasion. But our estimates also capture interdependence in justice votes due to any-other team-production based phenomena such as horsetrading (i.e. vote trading) or aversion to being in the minority and the effort of writing a dissent. Accordingly, in addition to capturing narrowly-defined peer persuasion effects, our estimates also speak to the process by which group production of decisions occurs on the Court.

As well as being of intrinsic interest, the Supreme Court is a context where, prima facie, peer effects appear difficult to isolate. Unlike some legal contexts where judges are plausibly randomly assigned to cases, the Supreme Court involves a panel of nine justices that evolves very slowly over time, and typically hear cases en banc, suggesting there is little variation in peer composition to exploit. Further, attempts to identify factors that exogenously shock a given justice's vote in a case in order to analyse peer effects are subject to the common shock problem. Simply put, the most salient factors that affect any justice's vote in a case are likely to directly affect all justices.

Despite this challenge, we argue that careful consideration of the institutional environment of the Court enables peer effects to be identified. Several features of the Court are pertinent. First, the relevant peer group of a justice can be clearly defined as the group of eight other justices who sit on the same Court. ${ }^{4}$ Second, even though the full complement of peers is fixed (except in the infrequent instances when court composition changes) we will show there exists a highly plausibly source of case-to-case exogenous variation in any one justice's peer group. A little known fact, at least outside the legal community, is that many Supreme Court cases are decided by less than the full complement of justices. That is, justices are frequently absent from particular cases due to illness, recusals, and other random factors. This stochastic process creates plausibly exogenous variation in justices' peer groups on a case-to-case basis.

Third and finally, the existence of "home court bias" generates a plausibly exogenous instrument that shifts the behavior of individual peer justices while the peer group is held exogenously fixed. Specifically, many Supreme Court justices previously sat on Federal Circuit Courts of Appeals. Epstein et al. (2009) find strong evidence that justices are highly inclined to rule in favor of

\footnotetext{
${ }^{4}$ If we view the whole set of justices as the peer group, the group selection problem is largely irrelevant as justices have minimal choice over the identity of their peers (except via retirement decisions). Furthermore, this peer group is of policy interest, as it can be altered by a well-defined policy lever (i.e., presidential nomination and Senate confirmation).
} 
their respective home circuit court, even conditional on ideology and other factors, and we find the same effect. This provides us with a compelling instrument to identify peer effects.

Together, these three facts mean that the question "How does the ideology or voting behavior of a justice's peers affect his/her own vote?" is well-posed, as the peer group is well defined, it is not self-selected, and it is subject to plausibly exogenous variation. And in addition, the behavior of peers is subject to plausibly exogenous variation induced by home court bias. Furthermore, this question is of policy relevance, because it helps to predict the impact of any potential Supreme Court appointment on the overall voting behavior of the Court.

In this paper we look at two types of peer effects: how peer ideology affects a justice's voting behavior, and how actual peer votes affect a justice's voting behavior. Following the literature, we will refer to these two types of peer effects as "exogenous" and "endogenous" peer effects, respectively (see, e.g., Moffitt, 2001).

First, in Section 3, we consider a model of "exogenous" peer effects where justice voting behavior is determined both by their own ideology and the ideology of their peers. Specifically, we utilize a detailed coding of the votes in our dataset as being either conservative (1) or liberal (0) in orientation, and then estimate a linear probability model of justice votes as a function of case characteristics, justice fixed effects (i.e., ideological positions), and mean peer ideology (constructed as the mean of peer justice fixed effects). Relying for identification primarily on changes in Court composition due to recusals and absences, we find clear evidence of ideology-based exogenous peer effects. In particular, we find that replacing a single justice with one who votes conservative 10 percentage points more frequently increases the probability that each other justice votes in the conservative direction by 1.63 percentage points (on average).

We then turn attention to investigating the possibility that peer effects may also be "endogenous," meaning they operate through the actual votes cast by peer justices, not their ideology per se. In that case, identifying a true peer effect requires exogenous variation in voting propensity across justices - i.e. a variable which directly affects how a given peer justice votes in a given case, but not the votes of other justices, except through the vote of the directly-affected peer. We argue that the "home court bias" instrument described earlier has these properties. 
Properly investigating whether "endogenous" peer effects exist requires simultaneously testing for both "exogenous" and "endogenous" channels. This corresponds to the two terms in the most general "structural" model of peer effects discussed in Moffitt (2001) equation 16. As Moffitt (2001) and Manski (1993) note, in the reduced form of this structural model, own votes depend on own ideology, peer ideology, and the exogenous factor (i.e., home court bias) that shifts peer votes conditional on ideology. In the absence of endogenous peer effects, the exogenous factor that shifts peer votes drops out of the reduced form. Thus, testing for significance of the "home court" bias of peers in the reduced form is a simple test for existence of endogenous peer effects (a test that should not be too sensitive to the exact functional form through which peer votes operate). When we estimate this reduced form (Section 4.3) we find both peer ideology and home court bias of peers are significant, implying both exogenous and endogenous peer effects are present.

Hence, in Section 4.4, we estimate structural models with both exogenous and endogenous peer effects, relying on both recusals and home court bias as sources of exogenous variation. In our preferred model, we find a percentage point increase in the proportion of peers casting conservative votes in a case makes a justice 0.9 percentage points more likely to vote conservative.

Finally, we examine whether peer effects change pivotal votes, and hence case outcomes, or if they merely affect the size of the majority. If peer effects merely push a decision from 6-3 to 5-4, or vice versa, then they are of limited practical interest. ${ }^{5}$ To address this question, we aggregate votes at the case level, and consider how a single justice's vote affects the collective voting behavior of their peers. We find strong evidence that peer effects can be pivotal. By affecting the votes of their peers, a single justice becoming 10\% more likely to vote conservative increases the share of cases with a conservative outcome by 3.6 percentage points-excluding the mechanical effect of that justice's own vote-and reduces the share with a liberal outcome by 3.2 percentage points.

We are certainly not the first authors to consider the issues of judicial ideology and peer effects. Many political science and legal scholars have debated whether Supreme Court decision making is largely driven by justices' own narrow policy preferences, or whether justices are also constrained by higher legal principles, such as deference to precedence and judicial restraint (Bai-

\footnotetext{
${ }^{5}$ Of course, the credibility of the Court, and how political it looks, is an important issue, and is plausibly affected by the size of the majority in a case. 5-4 decisions breaking along the lines of the party of the appointing President, for instance, may be seen as particularly political and this could be damaging to the image of the Court.
} 
ley and Maltzman (2011)), or political constraints, such as public opinion and executive discretion over compliance (Carrubba and Zorn (2010)). There is a significant empirical literature estimating the ideological position of judges and justices on measures that encapsulate both viewpoints. For instance, Martin and Quinn (2002) develop a dynamic item response model and estimate justice ideal points that can be time-varying, and Martin et al. (2005) use the Martin-Quinn method to estimate the median Supreme Court justice on Courts dating from 1937. If one thinks that peer effects operate through the characteristics of judges, then understanding judicial ideology is a necessary first step to study them, as well as being (arguably) of interest in its own right.

Perhaps closer to our paper is the literature on panel effects on lower courts. A large literature considers peer effects (often referred to as "panel effects") on U.S. Circuit Courts of Appeals. ${ }^{6}$ Different authors emphasize different channels, such as: deliberation, group polarization, or aversion to dissent (Epstein et al. (2011)). Fischman (2015) argues that peer effects are best understood by reference to peers' votes rather than characteristics, and reanalyzes 11 earlier papers on Circuit Court "panel" voting, as well as new data. ${ }^{7}$ He finds that-across the board-each judge's vote increases the probability that a given judge votes in the same direction by approximately 40 percentage points. Boyd et al. (2010) considers the impact of female judges and only finds strong effects for sex discrimination cases, suggesting an information channel is operative rather than alternative theories of influence (see also Peresie (2005)). Epstein and Jacobi (2008) argue the power of the median justice is due to bargaining power, not personality, and that ideological remoteness of the median justice makes them pivotal over a greater range of the ideological spectrum.

Relative to this literature, we make several contributions: One, we focus on the United States Supreme Court rather than U.S. Circuit Courts of Appeals. Two, we analyze both the ideological channel and the vote channel using a novel identification strategy. And three, we focus on both peer effects and their impact in altering case outcomes. Methodologically, we also prevent a simple new method for to estimate models where peer effects operate through fixed effects of peers.

Once one is convinced that peer effects exist, a key question is what drives them. In the context of lower courts, several possibilities have been raised, including: deliberation, group po-

\footnotetext{
${ }^{6}$ Some notable papers in this literature are Revesz (1997), Miles and Sunstein (2006) and Posner (2008).

${ }^{7} \mathrm{He}$ replaces the characteristics of panel colleagues with their votes, so the votes are endogenous, but colleague characteristics can be used as an instrument for colleague votes, assuming that they have no direct causal effect.
} 
larization, and aversion to dissent. Our paper is primarily about testing for existence of peer effects, not isolating the mechanisms through which they operate. But we touch on that question in our concluding remarks, where we also offer estimates of peer effects by issue area.

The paper is organized as follows: Section 2 describes the data. Section 3 presents our analysis of the ideological channel for peer effects, while Section 4 studies the ideological and voting channels jointly. Section 5 examines peer effects on case outcomes, and Section 6 concludes.

\section{Data on Supreme Court Votes}

The Supreme Court Database, developed by Spaeth and Epstein (2014), contains almost the entire universe of cases decided by the Court between the 1946 and 2013 terms. ${ }^{8}$ It provides detailed information on each case, including the participants, the legal issue area, the court term in which the case was heard and opinions were issued, the winning party and the vote margin. The data includes the identity and voting decision of each justice, for each case in which they were involved. This us to model the votes of individual justices, and how they relate to the identity and voting decisions of the peers. For almost all cases, votes are categorized as ideologically liberal or conservative, with codification following an explicit set of rules. Exceptions to this occur in cases without any clear ideological underpinning.

We augment these data with biographical on justices from the U.S. Supreme Court Justices Database developed by Epstein et al. (2013). This provides information on which, if any, Circuit Court of Appeals a justice previously served on, and the length of their tenure on that court. This allows us to construct our "home court bias" instrument.

In total, these data provide information on 116,362 votes (including absences and recusals) from 12,981 cases. Once we exclude exclude absences, recusals and cases without any ideological direction, the data contain 110,729 votes from 12,779 cases. ${ }^{9}$ One quarter of these cases involve a vote by less than the full panel of nine serving justices. Votes are ideologically balanced, with $48 \%$ issued in the conservative direction. In contrast, a slight majority $(55 \%)$ of lower court decisions

\footnotetext{
${ }^{8}$ E.g., per curiam decisions are not included unless the Court provided a summary, or opinions were issued.

${ }^{9} \mathrm{~A}$ small number of cases result in tied votes, following which the votes of individual justices are typically not made public. Provided that the case had a lower court decision with stated ideological direction, so that the case is known to have ideological relevance, the vote direction for each justice is coded as 0.5 by convention.
} 
Table 1 - Descriptive Statistics for Directional Votes

\begin{tabular}{lrrccc}
\hline \hline Votes & Cases & $\begin{array}{c}\text { Vote Direction } \\
\text { (Cons. \%) }\end{array}$ & $\begin{array}{c}\text { Lower Court } \\
\text { (Cons. \%) }\end{array}$ & $\begin{array}{c}\text { Overturn } \\
(\%)\end{array}$ \\
\hline Total & 110,729 & 12,779 & 47.58 & 55.03 & 58.18 \\
Legal Issue Area & & & & & \\
Criminal Procedure & 22,549 & 2,585 & 52.12 & 63.07 & 60.23 \\
Civil Rights & 18,435 & 2,112 & 44.87 & 53.47 & 58.71 \\
First Amendment & 9,895 & 1,140 & 45.92 & 56.66 & 56.25 \\
Due Process & 4,975 & 577 & 42.57 & 53.65 & 59.84 \\
Privacy & 1,483 & 169 & 60.35 & 30.21 & 57.38 \\
Attorneys & 1,122 & 130 & 43.23 & 52.05 & 60.34 \\
Unions & 4,387 & 506 & 45.25 & 57.53 & 55.87 \\
Economic Activity & 21,447 & 2,500 & 42.28 & 48.82 & 57.20 \\
Judicial Power & 17,041 & 1,976 & 58.32 & 54.18 & 58.33 \\
Federalism & 5,805 & 670 & 43.65 & 56.66 & 58.23 \\
Federal Taxation & 3,415 & 394 & 29.49 & 56.78 & 52.71 \\
& & & & & \\
Circuit Court & & & & & \\
Federal & 937 & 107 & 46.21 & 43.00 & 62.82 \\
First & 2,125 & 246 & 47.01 & 40.82 & 51.40 \\
Second & 8,107 & 934 & 48.35 & 50.70 & 54.85 \\
Third & 5,008 & 575 & 51.54 & 49.84 & 54.21 \\
Fourth & 4,471 & 512 & 45.96 & 60.88 & 55.40 \\
Fifth & 7,907 & 914 & 43.49 & 65.12 & 60.88 \\
Sixth & 5,558 & 644 & 47.59 & 50.55 & 60.17 \\
Seventh & 5,523 & 645 & 42.97 & 59.07 & 58.63 \\
Eighth & 4,046 & 465 & 45.30 & 48.60 & 57.94 \\
Ninth & 1,359 & 54.30 & 38.27 & 62.80 \\
Tenth & 367 & 51.03 & 51.22 & 60.01 \\
Eleventh & 247 & 44.80 & 67.68 & 57.10 \\
D.C. & 818 & 52.15 & 51.13 & 59.46 \\
\hline \hline
\end{tabular}

reviewed by the Supreme Court are in the conservative direction. There is a strong tendency towards overturning lower court decisions; $60 \%$ of Supreme Court decisions and 58\% of individual justice votes are for reversal. The Supreme Court only reviews a small fraction of cases, so of course it tends to hear cases where several justices believe the lower court may have erred.

Table 1 breaks down vote directions by legal issue area. Of the 11 high-level issue-areas in the database with a nontrivial number of cases, the conservative vote share over the 1946-2013 range of court terms varies from $29 \%$ conservative for Federal Taxation cases to $60 \%$ conservative in Privacy cases. Grouping instead by the Circuit Court of Appeals that previously heard the case (for the $\sim 60 \%$ of cases that source from such a court) the conservative share of votes ranges 
from $43 \%$ for cases from the Seventh Circuit to $54 \%$ for Ninth Circuit cases. The variation in vote ideology is much greater across justices: the conservative vote share ranges from $22 \%$ for William O. Douglas to $72 \%$ for Clarence Thomas (see Table 2 for details). Appendix C Figure 3 shows that the conservative vote share has varied substantially over time.

\section{Exogenous Ideology-Based Peer Effects}

First we assume exogenous peer effects. That is, we assume peer effects work directly through ideological positions, with the votes of one justice directly influenced by the ideological positions of the other justices. In the terminology of Manski, this is a contextual peer effect as justice ideology is predetermined with respect to interactions with other justices. Under this mechanism, the voting decisions of a particular justice are influenced by the ideological positions of peer justices, regardless of how those peer justices actually vote in a particular case.

\subsection{Model and Estimation Method}

We assume justices' votes are influenced by their own ideology, the factual context of the case, and the ideology of peers. The ideological direction of the vote by justice $j$ in case $c$, which we denote by $d_{j c}$, is either conservative (1) or liberal (0). Let $p\left(d_{j c}=1\right)$ denote the probability that justice $j$ votes in a conservative direction on case $c$. Then, we have the linear probability model:

$$
p\left(d_{j c}=1 \mid \alpha_{j}, \alpha_{-j}, \beta, \delta, X_{c}, I_{j c}\right)=\alpha_{j}+\beta_{p} \times \frac{1}{\left|I_{j c}\right|} \sum_{i \in I_{j c}} \alpha_{i}+X_{c}^{\prime} \beta+\delta_{t(c)}
$$

Here $\alpha_{j}$ is a justice fixed effect that captures justice ideology. The term $\frac{1}{\left|I_{j c}\right|} \sum_{i \in I_{j c}} \alpha_{i}$ is the mean ideology of the set of peer justices who are involved in case $c$, where $I_{j c}$ denotes the set of peers of justice $j$ in case $c$. Crucial, this set of peers varies across cases in a way we argue is plausibly exogenous. The term $\delta_{t(c)}$ is a fixed effect for the court term $t(c)$, meant to account for systematic changes in justice ideology over time. $\beta_{p}$ captures the effect of mean peer ideology. A positive coefficient indicates that judges are pulled towards the (mean) ideological position of their peers. ${ }^{10}$

\footnotetext{
${ }^{10}$ We argue that the mean ideology of peers is a sensible way to measure peer effects. As peers compete for influence, each should have greater weight the fewer peers are present. Conversely, if the influence of each peer does not decline at least proportionately as the number of peers increases, one obtains the odd implication that very large groups should
} 
Note that the vote probability $p\left(d_{j c}=1\right)$ is a nonlinear function of the vector of peer justice ideologies $\alpha_{-j}$ because the influence of the latter is case specific, depending on the set $I_{j c}$. Indeed, if the peer ideology term $\frac{1}{\left|I_{j c}\right|} \sum_{i \in I_{j c}} \alpha_{i}$ were simply a linear function of peer ideologies, as in $\frac{1}{8} \sum_{i} \alpha_{i}$, i.e., if the peer group did not vary, then we could not identify the impact of own ideology on justice votes as distinct from the impact of peers.

We may estimate equation (1) by nonlinear least squares (NLLS) as in:

$$
\min _{\alpha, \beta, \delta} \sum_{c, j}\left[d_{j c}-p\left(d_{j c}=1 \mid \alpha, \beta, \delta, X_{c}, I_{c j}\right)\right]^{2}
$$

At first glance this seems like a complex problem as we must search over the entire vector $\alpha$ of 36 justice ideologies, along with the other model parameters. In Appendix A we present a simple and fast iterative procedure to solve the NLLS problem. This procedure converges to the solution in three iterations, each of which only requires running a linear regression. ${ }^{11}$

\subsection{Empirical Specification}

Our baseline specification in (1), which we call "Model 1," includes a fixed effect to capture justice ideology, and term fixed effects $\delta_{t(c)}$ to capture systematic ideological drift over time. The vector $X_{c}$ of observable case characteristics includes the legal issue area, fixed effects for the Circuit Court of Appeals (if any) that previously heard the case, and the ideological direction of the decision made by the lower court. Also, we control for whether the case sourced from a Circuit Court of Appeals for which the justice previously served, and the number of years of that service, if any. These latter two variables are also interacted with the decision of the lower court.

We also consider two generalizations of our baseline specification. First, we allow for richer models of justice ideology. Ideology may be multidimensional, differing by issue area. To capture this, in Model 2, we incorporate justice by legal issue area fixed effects $\alpha_{j}^{l}$, where $l$ denotes issue area (replacing the $\alpha_{j}$ in Model 1). Ideology may also vary over time. For instance, if there is non-systematic ideological drift, such as polarization where conservative and liberal justices

exhibit near unanimity in making decisions, so long as positive peer effects exist.

${ }^{11}$ In earlier versions of this paper we presented a simple two-step procedure that gives estimates of $\beta_{p}$ that are subject only to a mild scale bias. In Appendix A we explain why a third iteration solves the NLLS problem. Correct standard errors may be obtained using the Hessian of the NLLS objective evaluated the solution. In practice this is irrelevant because the justice fixed effects are so precisely estimated, due to the large number of decisions we observe. 
move towards the extremes. Thus, Model 3 further allows justice ideology to vary over time, by including justice by issue area by "natural court" fixed effects $\alpha_{j}^{l, n c}\left(\right.$ replacing $\left.\alpha_{j}^{l}\right){ }^{12}$

Second, we allow for correlated shocks to all justices on the court at a given time. This is a common problem in peer effect regressions. If justice votes or ideology are subject common shocks, it may lead to a spurious finding of of peer effects. In our base specification (Model 1), we deal with this by including term fixed effects to absorb common ideological drift of justices over time. But if there exists systematic ideological drift that differs by issue area, it will not be fully absorbed by $\delta_{t(c)}$. Accordingly, in Models 2 and 3, we add issue area by term fixed effects $\delta_{t(c)}^{l}$ to account for any such differential ideological drift.

We also consider alternative specifications of the peer variable $\frac{1}{\left|I_{j c}\right|} \sum_{i \in I_{j c}} \alpha_{i}$ in equation (1). It is not a priori certain which justices should be included in the peer group $I_{c, j}$ for a particular case. For example, the pertinent set of peers could be all other justices on the Court, or just those who are active and vote in a case. Conversely, it is hard to rationalise why absent justices who do not vote in a case should matter. If they do, it would suggest that cases with absent justices differ in case unobservables, with justices having non-random selection into absence.

To investigate these issues, we estimate versions of all our models in which the peer group is defined as: (A) all other justices on the Court, (B) all other justices who are active and vote on a case (hereafter, active justices), (C) only the justices absent from a case, or (D) both active and absent justices. ${ }^{13}$ We view the coefficients on absent peer justice ideology as placebo tests to rule out the possibility that case unobservables drive our results (see Section 3.4 for details).

\subsection{Identification of Exogenous Peer Effects}

Before presenting our results, we discuss the source of the identifying variation exploited in the regressions, and the thought experiments that this variation correspond to. The key difficulty in identifying peer effects in the Supreme Court context is that there is little structural panel rotation. Unlike some other courts, cases do not involve random assignment of a subset of justices, and

\footnotetext{
${ }^{12} \mathrm{~A}$ natural court $n c$ is a period during which no personnel change occurs on the court.

${ }^{13}$ If multiple justices are absent, we argue their mean ideology is the natural measure of their potential influence. In regressions containing an absent peer justice term, the mean ideology of justices absent from a case is set to zero if no justices are absent. A dummy for the whether any justice was absent in the case is also added, to ensure the results are only identified using variation in the ideology of absent justices, and not an arbitrary normalization.
} 
further, the cohort of justices evolves slowly over time. Intuitively, these features complicate the task of separating peer effects from joint ideological drift of justices over time.

Consider the variation in peer ideology, as measured by the mean ideology of all other justices on the Court. In specifications with a single dimension of ideology (Model 1), the cohort of peers and thus the ideology of a given justice's peers only changes on the rare occasions when court composition permanently changes. And as term fixed effects absorb across term variation, identification relies only on mid-term retirements, deaths, and appointments of new justices. This condition also holds in Models 2 and 3, where ideology also varies by issue area, but where we include term by issue area fixed effects. In these cases the ideal thought experiment is comparing how the eight continuing justices vote in two otherwise identical cases in a term, when the ninth justice present in the first case retires and is replaced by a different justice for the second case. Needless to say, such changes in composition are rare, there is little of this variation to exploit, and the estimates of the effects of the ideology of all peers are thus under-powered.

Accordingly, we focus attention on our second peer measure, namely the mean ideology of other active justices. As we noted in Section 2, at least one justice is absent in roughly $1 / 4$ of all cases. This provides a natural source of within-term variation in the set of peers from case to case. Furthermore, peer ideology as measured by active peers varies substantially within term irrespective of whether ideology is measured by justice, or by justice-issue area pair.

While official reasons for absence are in general not publicly stated, typical reasons include illness, not being confirmed to the Court at the time oral argument took place (for mid-term appointments), or recusal if a justice has heard the case on a lower court, argued it in a previous role as US solicitor general, or owns stock in a firm affected by the case. Our identification strategy primarily leverages this case-by-case variation in court composition to isolate the effect of peer ideology on justice votes. Here, the ideal thought experiment is to compare how the common seven justices vote in two otherwise identical cases that differ only in that justice $j$ is absent in the former and justice $k$ is absent in the latter. ${ }^{14}$

\footnotetext{
${ }^{14}$ An alternate thought experiment is comparing the votes of the remaining eight justices in two otherwise identical cases except that justice $j$ is present in the first and absent in the second.
} 


\subsection{Testing the Exogeneity of Justice Absences}

In estimating peer effects using absence-based variation in peer ideology, it is necessary to address concerns regarding whether justice absences are exogenous. If justices' participation decisions are correlated with case unobservables that affect votes (such as latent ideological attributes of the case), then variation in court composition is tainted by selection bias. Then, vote directions may be spuriously correlated with the ideology of active peer justices. Concerns about potential selection bias are more acute if justices can exercise substantial discretion in choosing when to be absent, as their decision may depend on case characteristics unobservable to the econometrician. We pursue two approaches to deal with this concern. One is to implement an estimation procedure that is robust to non-random selection into absence. The second is to demonstrate that, upon analysis, there does not appear to be any correlation between unobserved vote probabilities and the ideology of absent justices, such that absences are as-good-as random.

Our first approach is to construct placebo tests which separate selection bias from the true peer effect of altering the composition of peers involved in a case. Variation in court composition due to absences allows us to estimate the effect of peer ideology both when peers are active (voting on a case) and absent. Intuitively, direct causal peer effects from a justice's ideology are plausible when justices participate and vote in a case. Conversely, any peer effect should be sharply attenuated or eliminated when a justice does not vote (i.e. if recused, it would be considered improper for them to discuss the case with the other justices). ${ }^{15}$ But if absences are strategic, ideology of absent justices may still be significant due to correlation with unobserved case characteristics.

We also consider a specification where we control for both active and absent peer ideology, so as to estimate the effect of variation in active peer ideology holding the ideology of absent peers constant. ${ }^{16}$ Here, the placebo test null-hypothesis of no selection bias is that controlling

\footnotetext{
${ }^{15}$ Of course, an absent peer may matter because their ideology influences a justice's way of thinking in an enduring manner. However, permanent peer effects like this will be largely absorbed by justice and term FE, and thus will not be captured by a measure of absent peer ideology, nor in general identified by these tests. Thus our method at best captures only some of the channels through which peer effects may operate.

${ }^{16}$ Within a given cohort, the mean ideology of active and absent peer justices will tend to be negatively correlated by construction. The two peer measures are not, however, colinear, as the absence of a particular justice causes the ideology of active peers to change differentially for each remaining justice. This happens even though the absent peer measure is common, because each of their remaining peers (the set of which is unique to each justice) receives a higher weighting overall. Separately identifying the active and absent peer measures is further aided by a handful of permanent changes in court composition. For example in periods between the death of a justice and their replacement being appointed, the composition of active justices is altered but the departed justice is not considered absent (as they are no longer a
} 
for the ideology of active peers, absent justice ideology should not affect votes. To foreshadow the results, we do not find meaningful evidence that absent justice ideologies can help to predict active justice votes (whether or not we control for active peer ideology).

Our second approach to the issue of selection bias is a direct empirical analysis of whether the ideology of absent justices is related to unobserved case characteristics. Previous analysis of the empirical determinants of justice absences on the Supreme Court, such as Black and Epstein (2005) and Hume (2014), suggests that many absences are largely non-discretionary. Examples include oral arguments occurring prior to a justice being appointed to a court, extended illness, or a case having already been heard by a justice while serving on a lower court. These absences are either plausibly independent of the affected cases, or well explained by observable characteristics (e.g. the circuit court that decided the case). However, for the remaining more discretionary absences, it is harder to give this guarantee a priori. Accordingly, while these papers find no evidence that absent justice ideology is endogenous, they cannot rule it out either.

Intuition suggests that justices would be less inclined to recuse themselves from cases they perceive as more important or likely to be closely-decided, irrespective of how they plan to vote. ${ }^{17}$ However, it is important to note that non-random occurrence of absences alone is not sufficient to produce endogeneity bias; this additionally requires that the ideology of the absent justice(s) be non-random and correlated with counterfactual vote probabilities.

This insight suggests a simple test: Approximately one-quarter of the cases with an absent justice (721 of 2,917) involve multiple absences. If absences are correlated with ideology, then in cases with multiple absences the absent justices should tend to share similar ideologies. If $k$ of $N$ justices are absent in a case, the obvious thought experiment is the extent to which, given the ideology of $k-1$ absent justices, the ideology of the final absent justice out of the remaining $N-k+1$ justices can be predicted. We can test this by regressing the ideology of each absent justice in turn against the mean ideology of the other absent justices, controlling for the mean ideology of the $N-k-1$ remaining justices (that is, the $N-k$ active justices plus the final absent justice, member of the court at the time a case is considered).

${ }^{17}$ Indeed, Black and Epstein (2005) find that recusals are less frequent in (typically higher-stakes) cases where the underlying issues have generated disagreement among different lower courts, and more likely in (typically lowerstakes) cases pertaining to statutory (rather than constitutional) interpretation. 
as this is akin to the remaining pot from which a justice is selected without replacement).

Complicating matters is that selection is not the only reason absent justices may share similar ideology. A substantial number of multiple absences arise from a few instances where multiple justices sharing similar ideology were appointed in rapid succession by the same president. Accordingly, we run the above regressions separately for first term absences (where this mechanism is at play) and later absences (where it is not). Using the the justice ideology estimates we report below in Table 2, we find the coefficient on the mean ideology of other absent justices is 0.40 (SE 0.05) for first term absences, whereas it is a minuscule -0.0002 (SE 0.11) for later absences. Hence we find no evidence that absences are endogenous.

\subsection{Peer Ideology Effect Estimates}

The main results for our exogenous peer effects models are reported in Tables 2, 3 and 4 . Table 2 reports the estimates of the justice fixed effects, Table 3 reports the estimates of the control variables, while Table 4 reports the key parameters that measure peer effects.

Table 2 reports our estimates of justice fixed effects from Model 1B. Recall that Model 1 includes justice fixed effects, but it does not allow these to vary by issue area or term. And version B of this model uses active peers as the peer effects measure. In Table 2 we order all 36 justices from the 1946-2013 period according to their estimated ideology, from most liberal to most conservative. In reading the table, recall that a conservative case outcome is recorders as 1, so a higher fixed effect estimate implies the justice is more conservative. The estimates are intuitive, with Douglas rated the most liberal $(\mathrm{FE}=0.20)$ and Thomas the most conservative $(\mathrm{FE}=0.83) .{ }^{18}$ Table 2 also lists some observed justice characteristics: As expected, justices who we estimate to be more conservative also tend to have lower (more conservative) Segal-Cover scores, higher conservative vote proportions and were more likely to have been nominated by a Republican president.

Table 3 reports estimates of the coefficients on the control variables in equation (1). We report the results for Models 1B through 3B, which include successively richer controls for issue area

\footnotetext{
${ }^{18}$ Recall that Model 1 controls for term fixed effects, so justice ideology estimates abstract from joint ideological drift in the views of justices, and secular changes in the ideological composition of cases heard by the Supreme Court. Thus, rather than ranking justice ideology in an absolute sense, the fixed effects in Table 2 measure the ideology of justices relative to their social milieu. By accounting for time effects that would affect any justice serving in an equivalent context, these ideology scores are interpretable as estimating the relative ideologies of any set of justices had they counterfactually been on the Supreme Court at the same time.
} 
Table 2 - Justice Ideology Fixed Effects and Justice Characteristics

\begin{tabular}{|c|c|c|c|c|}
\hline Justice & $\begin{array}{l}\text { Ideology } \\
\text { Estimate }\end{array}$ & $\begin{array}{l}\text { Segal-Cover } \\
\text { Score }\end{array}$ & $\begin{array}{c}\text { Conservative } \\
\text { Vote Share }\end{array}$ & $\begin{array}{l}\text { Party of } \\
\text { President }\end{array}$ \\
\hline W. O. Douglas & 0.1969 & 0.730 & 0.2154 & Democratic \\
\hline W. B. Rutledge & 0.2042 & 1.000 & 0.2336 & Democratic \\
\hline F. Murphy & 0.2137 & 1.000 & 0.2424 & Democratic \\
\hline T. Marshall & 0.2435 & 1.000 & 0.2802 & Democratic \\
\hline W. J. Brennan & 0.2728 & 1.000 & 0.2930 & Republican \\
\hline H. L. Black & 0.2775 & 0.875 & 0.2820 & Democratic \\
\hline A. Fortas & 0.2830 & 1.000 & 0.3082 & Democratic \\
\hline E. Warren & 0.2896 & 0.750 & 0.2703 & Republican \\
\hline A. J. Goldberg & 0.3092 & 0.750 & 0.2404 & Democratic \\
\hline J. P. Stevens & 0.3976 & 0.250 & 0.3889 & Republican \\
\hline R. B. Ginsburg & 0.4468 & 0.680 & 0.3863 & Democratic \\
\hline S. Sotomayor & 0.4748 & 0.780 & 0.3712 & Democratic \\
\hline D. H. Souter & 0.4749 & 0.325 & 0.4183 & Republican \\
\hline H. A. Blackmun & 0.4755 & 0.115 & 0.4790 & Republican \\
\hline S. G. Breyer & 0.4853 & 0.475 & 0.4160 & Democratic \\
\hline E. Kagan & 0.5034 & 0.730 & 0.3963 & Democratic \\
\hline P. Stewart & 0.5179 & 0.750 & 0.5046 & Republican \\
\hline T. C. Clark & 0.5241 & 0.500 & 0.4764 & Democratic \\
\hline B. R. White & 0.5345 & 0.500 & 0.5201 & Democratic \\
\hline F. M. Vinson & 0.5681 & 0.750 & 0.5635 & Democratic \\
\hline F. Frankfurter & 0.5735 & 0.665 & 0.5394 & Democratic \\
\hline S. Minton & 0.5974 & 0.720 & 0.5688 & Democratic \\
\hline S. F. Reed & 0.5998 & 0.725 & 0.5708 & Democratic \\
\hline H. H. Burton & 0.6030 & 0.280 & 0.5669 & Democratic \\
\hline L. F. Powell & 0.6070 & 0.165 & 0.6084 & Republican \\
\hline C. E. Whittaker & 0.6102 & 0.500 & 0.5516 & Republican \\
\hline R. H. Jackson & 0.6192 & 1.000 & 0.6157 & Democratic \\
\hline J. Harlan II & 0.6269 & 0.875 & 0.5729 & Republican \\
\hline W. E. Burger & 0.6605 & 0.115 & 0.6574 & Republican \\
\hline S. D. O'Connor & 0.6790 & 0.415 & 0.6245 & Republican \\
\hline A. M. Kennedy & 0.6918 & 0.365 & 0.6042 & Republican \\
\hline J. G. Roberts & 0.7374 & 0.120 & 0.6126 & Republican \\
\hline W. H. Rehnquist & 0.7640 & 0.045 & 0.7134 & Republican \\
\hline A. Scalia & 0.7813 & 0.000 & 0.6793 & Republican \\
\hline S. A. Alito & 0.8020 & 0.100 & 0.6653 & Republican \\
\hline C. Thomas & 0.8293 & 0.160 & 0.7157 & Republican \\
\hline
\end{tabular}

The ideology estimates are the fixed effects estimates form Model 1B, which includes justice, issue area and term fixed effects, and relies on the mean active peer ideology measure. All models include circuit court fixed effects. $\mathrm{N}=110,729$ votes. ${ }^{*} \mathrm{p}<0.10,{ }^{* *} \mathrm{p}<0.05,{ }^{* * *} \mathrm{p}<0.01$

and term fixed effects (as discussed in Section 3.2) while using active peers to form the peer effects measure. Two aspects of the results are notable: First, the fact that the coefficient on the indicator 
Table 3 - Exogenous Peer Effect Models: Control Variables

\begin{tabular}{lccc}
\hline \hline & $(1)$ & $(2)$ & $(3)$ \\
\hline Lower Court Decision: & & & \\
Conservative & -0.061 & -0.088 & -0.092 \\
& $(0.041)$ & $(0.059)$ & $(0.061)$ \\
Liberal & $0.084^{* *}$ & 0.053 & 0.048 \\
& $(0.041)$ & $(0.059)$ & $(0.061)$ \\
Home Court Interaction with: & & & \\
Conservative Decision & $0.108^{* * *}$ & $0.123^{* * *}$ & $0.124^{* * *}$ \\
& $(0.031)$ & $(0.028)$ & $(0.028)$ \\
Conservative $\times$ Tenure & $-0.012^{* * *}$ & $-0.012^{* * *}$ & $-0.012^{* * *}$ \\
& $(0.004)$ & $(0.003)$ & $(0.003)$ \\
& & & \\
Liberal Decision & $-0.158^{* * *}$ & $-0.140^{* * *}$ & $-0.139^{* * *}$ \\
Liberal $\times$ Tenure & $(0.032)$ & $(0.031)$ & $(0.032)$ \\
& $0.016^{* * *}$ & $0.014^{* * *}$ & $0.014^{* * *}$ \\
& $(0.003)$ & $(0.003)$ & $(0.003)$ \\
Circuit Court FE & & & \\
Issue Area FE & Yes & Yes & Yes \\
Justice FE & Yes & & \\
x Issue Area & Yes & Yes & \\
$\quad$ x Natural Court & & & Yes \\
Term FE & Yes & Yes & Yes \\
x Issue Area & 0.1454 & 0.2111 & 0.2405 \\
\hline R-squared & & & \\
\hline \hline
\end{tabular}

The columns show results for Models 1B through 3B, which use progressively richer controls for justice, issue and court/term effects. All results are for models version $\mathrm{B}$ that use the mean active peer ideology measure. $\mathrm{N}=110,729$ votes. ${ }^{*} \mathrm{p}<0.10,{ }^{* *} \mathrm{p}<0.05,{ }^{* * *} \mathrm{p}<0.01$

for a conservative lower court decision is negative, while that for a liberal lower court opinion is positive, reflects the tendency of the Supreme Court to overturn many decisions that it reviews (hence reversing the ideological direction of lower court decisions).

Second, a consistent pattern of home court bias is evident. Consistent with results in Epstein et al. (2009), we find that justices who had previously served on a Circuit Court of Appeals (a justice's home court) are less likely to overturn the lower court's decision in a case sourced from that court. However this bias diminishes with home court tenure, and justices with very long Circuit Court tenures (i.e., more than ten years) are instead more likely to overturn lower court decisions when hearing a case sourced from their home court. 
We now turn to our key results; the estimates of peer ideology effects. The results for Models 1 to 3, which use progressively richer controls for justice, issue and term effects, are reported in the three panels of Table 4. Columns A through D of each panel show results for different specifications of the peer ideology measure, based on all peers, active peers, absent peers, or both.

The results for Model 1, which includes term and justice fixed effects - so that each justice has a single invariant ideology estimate - are shown in the first panel. Column A reports results using the mean ideology of all peers to measure peer effects. As expected, the estimate of the peer effect parameter $\beta_{p}$ is very imprecise, because Supreme Court panel rotation is infrequent and largely absorbed by term fixed effects, leaving little exogenous variation in peer ideology.

Table 4 - Exogenous Peer Effect Models: Peer Ideology Effect Parameter

\begin{tabular}{|c|c|c|c|c|}
\hline \multicolumn{5}{|c|}{ Model 1: Justice and Term Fixed Effects } \\
\hline & $(\mathrm{A})$ & (B) & (C) & (D) \\
\hline All Peer Justices & $\begin{array}{l}-0.874 \\
(1.073)\end{array}$ & & & \\
\hline Active Peer Justices & & $\begin{array}{c}1.131^{* * *} \\
(0.319)\end{array}$ & & $\begin{array}{c}1.244^{* * *} \\
(0.432)\end{array}$ \\
\hline Absent Peer Justices & & & $\begin{array}{l}-0.163^{*} \\
(0.086)\end{array}$ & $\begin{array}{c}0.033 \\
(0.102)\end{array}$ \\
\hline R-squared & 0.1446 & 0.1454 & 0.1450 & 0.1455 \\
\hline \multicolumn{5}{|c|}{$\begin{array}{l}\text { Model 2: Justice by Issue, and Term by Issue FE } \\
\end{array}$} \\
\hline All Peer Justices & $\begin{array}{c}0.030 \\
(0.797)\end{array}$ & & & \\
\hline Active Peer Justices & & $\begin{array}{c}1.082^{* * *} \\
(0.238)\end{array}$ & & $\begin{array}{c}1.199^{* * *} \\
(0.315)\end{array}$ \\
\hline Absent Peer Justices & & & $\begin{array}{c}-0.158^{* *} \\
(0.066)\end{array}$ & $\begin{array}{c}0.035 \\
(0.077)\end{array}$ \\
\hline R-squared & 0.2101 & 0.2111 & 0.2106 & 0.2112 \\
\hline \multicolumn{5}{|c|}{ Model 3: Justice by Issue by Court, and Term by Issue FE } \\
\hline All Peer Justices & $\begin{array}{l}-0.807 \\
(3.382)\end{array}$ & & & \\
\hline Active Peer Justices & & $\begin{array}{c}1.438^{* * *} \\
(0.300)\end{array}$ & & $\begin{array}{c}1.679^{* * *} \\
(0.496)\end{array}$ \\
\hline Absent Peer Justices & & & $\begin{array}{c}-0.269^{* * *} \\
(0.079)\end{array}$ & $\begin{array}{c}0.068 \\
(0.109)\end{array}$ \\
\hline R-squared & 0.2378 & 0.2405 & 0.2399 & 0.2406 \\
\hline
\end{tabular}

Note: $\mathrm{N}=110,729$ votes. ${ }^{*} \mathrm{p}<0.10,{ }^{* *} \mathrm{p}<0.05,{ }^{* * *} \mathrm{p}<0.01$. 
Table 4 column B presents results using our preferred active peers measure which exploits within-term variation in peers due to absences. This yields a substantial and tightly estimated active peer coefficient of 1.131. This implies, for example, that replacing a justice with another who votes in the conservative direction 10 percentage points more frequently on average would increase the conservative vote probability of all other justices by 1.41 percentage points, generating a cumulative 0.11 extra conservative votes by the peer justices per case (i.e., $0.0141 \times 8=0.11$ ).

Column $\mathrm{C}$ presents the absent peers placebo measure. The estimate is a small and marginally negatively significant, but this disappears when we jointly include both the active and absent peer measures in column D. Comparing columns B and D we see that inclusion of the absent peers measure causes the coefficient on active peer ideology to increase slightly to 1.244. This pattern suggests the slight negative coefficient on absent peers in column $C$ is merely an artifact of the negative within-term correlation between the ideologies of absent and active justices. ${ }^{19}$

The results for Model 2, which contains both justice by issue area and term by issue area fixed effects, are shown in the third panel of Table $4 .^{20}$ As in Model 1, the all peers ideology effect is very imprecisely estimated. However the active peer measure, which exploits within-year-andissue-area variation in peer ideology due to justice absences, yields a positive and significant peer effect coefficient of 1.082. The placebo measure of absent justices yields a significant albeit modest negative estimate in column $C$, and this placebo effect again disappears under joint estimation of the effects of active and absent peers (see column D).

Finally, the results for Model 3, which allows the ideology of each justice to change over time (by natural court) for each issue area, are displayed in the final panel of Table 4. In Column B we obtain a coefficient of 1.438 on our preferred peer measure, the mean ideology of active peers, with a standard error of 0.30 . In column $C$ the absent peer measure is significantly negative at -0.269 . However this again appears to be an artifact of the negative correlation between the ideology of absent and active peers; when the active peer measure is also included in column $\mathrm{D}$, the coefficient of the absent peer measure is near zero and insignificant.

\footnotetext{
${ }^{19}$ Notice that the standard errors of the active and absent peer variables only increase by about one-third when both are included together, compared to when each is included separately (compare columns C through D). This illustrates that there is not a high degree collinearity between these two variables (for reasons we discussed in Section 3.4).

${ }^{20}$ Once we introduce justice by issue area fixed effects, changes in court composition induce differential changes in peer ideology by issue area. This source of variation may not be well distinguished from issue-area-specific ideological drift over time. Thus, Model 2 absorbs this source of variation via inclusion of term-by-issue-area fixed effects.
} 
Viewed collectively, the results in Table 4 suggest the ideology of active justices has a substantial impact on the votes of their peers. Further, justice absences do not seem to convey information about the ideological disposition of cases, consistent with our identifying assumptions.

\subsubsection{Accounting for Potential Endogeneity of Ideology}

In Section 3.5 we estimate justice ideology from each justice's full voting record. A potential concern is that our ideology measures are not predetermined. However, this concern is simple to deal with by use of a predetermined measure of ideology as an instrument.

Segal-Cover scores, developed by Segal and Cover (1989) and reported in Table 2, are estimates of justice ideology based on textual analysis of newspaper editorials between nomination by the President and the Senate confirmation vote. They predate a justice's Supreme Court tenure, so they are predetermined with respect to voting behavior. As Table 2 reveals, Segal-Cover scores are very imprecise compared to our vote-based ideology measures. But they are clearly highly correlated with our measures, and should be independent of ex-post common shocks.

As Segal-Cover scores provide a single overall ideology estimate for each justice, we use them to instrument for the ideology estimates in Model 1. Table 5 reports the results, which are very similar to the Model 1 estimates in Table 4 top panel. In particular, the coefficient on active peer ideology in column B only moves slightly from 1.131 to 1.129. And the placebo specifications in columns C and D find statistically insignificant peer effects of absent justices. So the IV results provide additional evidence of positive peer ideology effects.

Table 5 - Instrumenting for Peer Ideology using Segal-Cover Scores

\begin{tabular}{lcccc}
\hline \hline \multicolumn{5}{c}{ Model 1: Justice and Term Fixed Effects } \\
& $(\mathrm{A})$ & (B) & (C) & (D) \\
\hline All Peer Justices & -1.847 & & & \\
& $(1.518)$ & & & \\
Active Peer Justices & & $1.129^{* * *}$ & & $1.061^{*}$ \\
& & $(0.427)$ & & $(0.582)$ \\
Absent Peer Justices & & -0.160 & -0.009 \\
& & & $(0.118)$ & $(0.136)$ \\
\hline \hline
\end{tabular}

Note: The mean Segal-Cover score of justices in each peer group (all, active or absent) is used to instrument peer ideology measure for that group. ${ }^{*} \mathrm{p}<0.10,{ }^{* *} \mathrm{p}<0.05,{ }^{* * *} \mathrm{p}<0.01$ 


\section{A Model with Both Exogenous and Endogenous Peer Effects}

Here we extend our analysis of to allow for vote-based peer effects, in addition to exogenous ideology-based peer effects. If peers affect the votes of their colleagues through their own votes, then the votes of all justices are jointly determined on a case-by-case basis, as in Fischman (2015). This fits within the framework of Manski's endogenous peer effects (Manski (1993)).

\subsection{Empirical Specification and Vote Endogeneity}

We begin by extending the model in equation (1) to incorporate peer effects that operate through peer votes. Recall that $d_{j c}$ is the vote of justice $j$ in case $c$, equal to 1 for votes in a conservative direction and 0 otherwise, and denote the set of peers who may affect justice $j$ through their votes in case $c$ as $V_{j c}$. Then we have the linear probability model:

$$
d_{j c}=\alpha_{j}+\beta_{p}^{v} \times \frac{1}{\left|V_{j c}\right|} \sum_{i \in V_{j c}} d_{i, c}+\beta_{p}^{i} \times \frac{1}{\left|I_{j c}\right|} \sum_{i \in I_{j c}} \alpha_{i}+\delta_{t(c)}+X_{c}^{\prime} \beta+\varepsilon_{j c}
$$

This equation is identical to the specification in Model 1 of Section 3, except that now $\beta_{p}^{i}$ captures the effect of the ideology of a justice's peers, while $\beta_{p}^{v}$ captures the effect of the votes of peers (and here we make explicit the idiosyncratic error term $\left.\epsilon_{j c}\right)$.

We consider three alternative specifications of the relevant peer group of justices $V_{j c}$ whose votes may affect the vote of justice $j$. First, and primarily, we consider the votes of all other justices who vote in a case (active justices, in the language of Section 3).

Second, peers who have special expertise in a case may have a greater influence. Justices who previously served on the appellate court from which a case is sourced are plausibly more knowledgeable. ${ }^{21}$ Accordingly, we also consider the votes of home justices in home court cases.

Third, as the impact of home peer votes may be stronger when they are more numerous, we also consider the net vote direction of the home justices (i.e.,the number of home justices issuing conservative votes minus liberal votes), divided by the total number of all active peers. ${ }^{22}$

\footnotetext{
${ }^{21}$ Circuit courts tend to hear cases in certain areas, so a judge from such a court will tend to have more expertise in those areas. Second, a former circuit court judge may be more familiar with the legal reasoning of its judges.

${ }^{22}$ For example, if there are three home peers, of which two vote liberal and the other conservative, the variable is ${ }^{-1 / 8}$. If there are two home peers, and both vote liberal, it equals $-2 / 8$.
} 
Obtaining consistent estimates of $\beta_{p}^{v}$ requires the use of instrumental variables, as votes are jointly determined. Of course, common unobservables that affect outcomes for both a person and their peers is a standard problem when estimating endogenous peer effects. Here, unobserved case characteristics are very important determinants of votes, so peer votes provide substantial information about the nature of a case. ${ }^{23} 37 \%$ of cases in our sample were decided unanimously, so the vote of a single justice has substantial predictive power for how other justices vote, irrespective of the existence of peer effects. To identify true peer vote effects it is necessary to find an instrument that generates exogenous variation in voting propensity across justices, unrelated to unobserved case characteristics. We explain our "home court" instrument in the next section.

\subsection{Constructing Instruments for Peer Votes}

Epstein et al. (2009) find that justices who had previously served on a Circuit Court of Appeals, their home court in our terminology, are ceteris paribus less likely to overturn decisions in cases sourced from their home court. Figure 1 documents this pattern by plotting the rate at which justices overturn decisions in cases from their home court relative to all other cases, against the duration of home court tenure, for each of the 19 justices who previously served on a Circuit Court of Appeals. All but 4 justices lie above the x-axis, indicating deference to home court decisions.

In Section 3, we used an indicator for whether a case was sourced from a justice's home court as a determinant of that justice's vote. Like Epstein et al. (2009), we find that justices who have previous service on a Circuit Court of Appeals are less likely to overturn decisions sourced from that "home court," but we find the effect diminishes with longer lower court tenure. ${ }^{24}$ Here we argue that variables that capture this effect can also be used as instruments for peer votes.

In particular, a valid instrument should affect how a justice votes in a given case only through its effect on a peer's vote (see Moffitt (2001)). The home court instrument plays this role, as there is no plausible reason the mere presence of a peer justice from a lower court would affect how another justice votes on a case sourced from that court. Any plausible effect must operate through

\footnotetext{
${ }^{23}$ The observed case characteristics are legal issue area, the term the case is heard, the lower court decision, and the Circuit Court (if any) the case stems from. Conditioning of these variables leaves much of the variation in case vote outcomes unexplained, implying that unobserved case characteristics are very important determinants of votes.

${ }^{24}$ In particular, Justices Kennedy and Berger both exhibit bias against their home courts, and both had long tenures: Kennedy served on the $9^{\text {th }}$ Circuit for 12 years, and Chief Justice Burger served on the D.C. Circuit Court for 13 years, often clashing with colleagues during his tenure, see Greenhouse (2007).
} 
how the home peer justice actually votes.

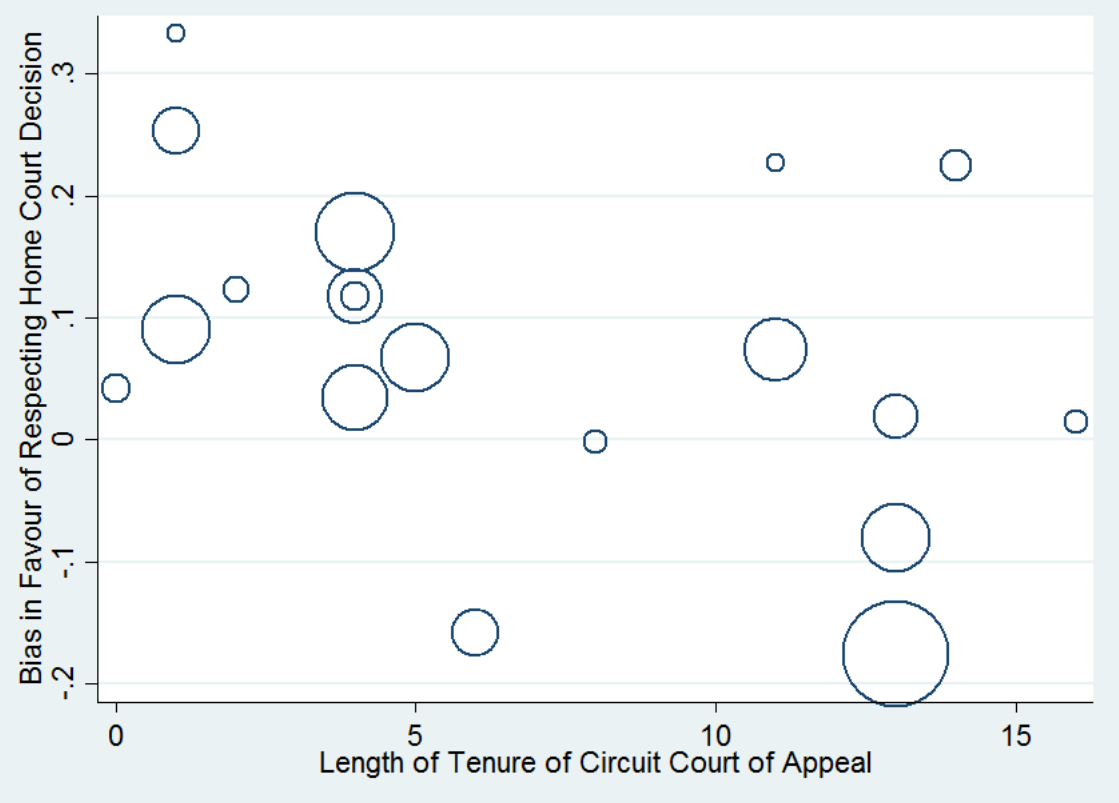

Figure 1 - Home Court Bias in Overturn Rate of Lower Court Decisions

To form the instruments, let $I_{c}^{a}$ denote the set of justices in case $c$ who previously served on lower court $a$, and let $y_{j}^{a}$ denote justice $j^{\prime}$ 's tenure on lower court $a$. Our instruments are the share of other justices at home $\frac{1}{N-1} \sum_{j \neq i} I\left(j \in I_{c}^{a}\right)$ and the average length of home court tenure per justice $\frac{1}{N-1} \sum_{j \neq i}\left(I\left(j \in I_{c}^{a}\right) \times y_{j}^{a}\right)$ in the case. ${ }^{25}$ Both are interacted with the lower court decision direction to convert effects on overturn propensity into effects on ideological disposition.

To negate any possibility that the instruments are contaminated by selection into absence, we construct them two ways. First, using only the justices active in a case, second using all justices on the Supreme Court. If there are no selection effects the former specification is more intuitive, as the endogenous peer vote variable in equation (3) is only based on active peer votes.

\subsection{A Simple Reduced-Form Test for Endogenous Peer Effects}

Before estimating the structural model in equation (3), we first present a simple reduced-form test for whether endogenous peer effects exist. To obtain the reduced form of (3), we substitute out for peer votes using all their exogenous determinants. In practice, this is equivalent to simply adding

\footnotetext{
${ }^{25}$ Note that we take the average over both home and away justices.
} 
the "home bias" instruments directly to equation (1). If these variables are jointly significant in the reduced form, we take it as evidence that endogenous peer effects exist.

Table 6 reports coefficients on the key variables of interest in the reduced from. We report results for Model 1 that includes justice and term fixed effects. The peer home court measures are jointly highly significant, as shown by the F-statistics. The sign pattern is consistent with the idea that the votes of home court peers dampen the propensity of the Supreme Court to overturn lower court verdicts, as the justices show some deference to peers from the lower court. It is implausible the home court variables would affect justices' votes directly, rather than indirectly through peer votes, so this is strong evidence that endogenous peer effects exist.

Table 6 - Reduced Form Model of Peer Effects

\begin{tabular}{|c|c|c|c|c|}
\hline & (A) & (B) & (C) & (D) \\
\hline All Peer Justices & $\begin{array}{c}-0.873 \\
(1.060)\end{array}$ & & & \\
\hline Active Peer Justices & & $\begin{array}{c}1.135^{* * *} \\
(0.319)\end{array}$ & & $\begin{array}{c}1.258^{* * *} \\
(0.432)\end{array}$ \\
\hline Absent Peer Justices & & & $\begin{array}{l}-0.162^{*} \\
(0.086)\end{array}$ & $\begin{array}{c}0.036 \\
(0.101)\end{array}$ \\
\hline Share of Peers on Lower Court & & & & \\
\hline$\times$ Conservative Decision & $\begin{array}{c}0.121 \\
(0.170)\end{array}$ & $\begin{array}{c}0.129 \\
(0.170)\end{array}$ & $\begin{array}{c}0.120 \\
(0.170)\end{array}$ & $\begin{array}{c}0.131 \\
(0.170)\end{array}$ \\
\hline$\times$ Liberal Decision & $\begin{array}{c}-0.477^{* * *} \\
(0.178)\end{array}$ & $\begin{array}{c}-0.488^{* * *} \\
(0.178)\end{array}$ & $\begin{array}{c}-0.478^{* * *} \\
(0.178)\end{array}$ & $\begin{array}{c}-0.489^{* * * *} \\
(0.178)\end{array}$ \\
\hline Peer Mean Tenure at Lower Court & & & & \\
\hline$\times$ Conservative Decision & $\begin{array}{l}-0.032 \\
(0.027)\end{array}$ & $\begin{array}{l}-0.032 \\
(0.027)\end{array}$ & $\begin{array}{c}-0.031 \\
(0.027)\end{array}$ & $\begin{array}{l}-0.033 \\
(0.027)\end{array}$ \\
\hline$\times$ Liberal Decision & $\begin{array}{c}0.070^{* * *} \\
(0.021)\end{array}$ & $\begin{array}{c}0.071^{* * *} \\
(0.021)\end{array}$ & $\begin{array}{c}0.071^{* * *} \\
(0.021)\end{array}$ & $\begin{array}{c}0.071^{* * *} \\
(0.021)\end{array}$ \\
\hline R-squared & 0.1454 & 0.1463 & 0.1458 & 0.1463 \\
\hline Instruments F-Statistic & 4.320 & 4.343 & 4.288 & 4.362 \\
\hline Instrument P-Value & 0.0017 & 0.0016 & 0.0018 & 0.0016 \\
\hline
\end{tabular}

All regressions include the same set of controls as in Model 1 in Table 3. $N=110,729$ votes. ${ }^{*} \mathrm{p}<0.10,{ }^{* *} \mathrm{p}<0.05,{ }^{* * *} \mathrm{p}<0.01$

Note that the active peer ideology measure is also significant in the reduced form, with coefficients that are little changed from those in the first panel of Table 4 . The significance of peer ideology in the reduced form may arise either because exogenous peer effects exist, or because peer ideology affects a justice's own vote through its effect on peer votes (i.e., an endogenous peer ef- 
fect). Thus our reduced form results may be consistent with a structural model that contains both exogenous and endogenous peer effects or one that contains only the latter. We must estimate the structural model in (3) to sort out these two explanations.

\subsection{Structural Model Results}

Our first stage results from regressing peer votes on the instruments are shown in Table 7. Column (1) presents our main specification, where the endogenous variable in equation (3) is the mean vote of all active peers, which is regressed on the home court instruments based on all active home justices. The instruments are highly significant determinants of peer votes $(F=5.37, p=0.000)$. The point estimates indicate that as the share of home peers increases, there are fewer peer votes to overturn the lower court (i.e., if the lower court decision was in the conservative (liberal) direction, the peer vote share in the conservative (liberal) direction increases). This effect is diminished if the home peers had longer tenure on the lower court. In column (2) we see the results are little changed if we base the instruments on all peers rather than only only active peers.

Columns (3) and (4) report first stage results for our alternative specification of the structural model in equation (3) where the endogenous variable is the mean vote of home peers only. Unsurprisingly, our home court instruments are even stronger in this model, as they are better predictors of home peer votes than of all peer votes. Finally, columns (5) and (6) reports results for our third version of the endogenous variable, the net vote of home peers.

We present our instrumental variable estimates of the full structural model of equation (3) in Table 8. The IV estimates document substantial positive peer effects. Columns 1 and 2 show that, ceteris paribus, a percentage point increase in the proportion of peers issuing a conservative vote in a case makes a justice 0.9 percentage points more likely to vote conservatively. In the typical full panel case (with 8 peer justices), this means that a single peer experiencing a 10 percentage point increase in conservative vote probability yields a direct effect of 1.1 percentage points on each other justice. Thus, the high correlation between justice votes is not due solely to unobserved case characteristics, but results in part from a causal impact of peer votes.

Columns 3 and 4 ask whether home justice votes are more influential than other peer votes, as would arise if home justices are perceived as having greater expertise in cases originating from 
Table 7 - First Stage IV for Peer Votes: Home Court Instruments

\begin{tabular}{|c|c|c|c|c|c|c|}
\hline & \multicolumn{2}{|c|}{ Active Peer Votes } & \multicolumn{2}{|c|}{ Home Peer Votes } & \multicolumn{2}{|c|}{ Net Home Peer Votes } \\
\hline & $(1)$ & $(2)$ & (3) & (4) & (5) & (6) \\
\hline \multicolumn{7}{|l|}{ Share of Peers at Home } \\
\hline$\times$ Conservative Decision & $\begin{array}{c}0.211 \\
(0.169)\end{array}$ & & $\begin{array}{l}0.385^{*} \\
(0.211)\end{array}$ & & $\begin{array}{l}0.178^{* *} \\
(0.090)\end{array}$ & \\
\hline$\times$ Liberal Decision & $\begin{array}{c}-0.582^{* * *} \\
(0.176)\end{array}$ & & $\begin{array}{c}-1.403^{* * *} \\
(0.229)\end{array}$ & & $\begin{array}{c}-0.280^{* * *} \\
(0.094)\end{array}$ & \\
\hline \multicolumn{7}{|l|}{ Peer Mean Years at Home } \\
\hline$\times$ Conservative Decision & $\begin{array}{l}-0.039 \\
(0.026)\end{array}$ & & $\begin{array}{c}-0.085^{* * *} \\
(0.030)\end{array}$ & & $\begin{array}{c}-0.025^{* * *} \\
(0.009)\end{array}$ & \\
\hline$\times$ Liberal Decision & $\begin{array}{c}0.079^{* * *} \\
(0.020)\end{array}$ & & $\begin{array}{c}0.217^{* * *} \\
(0.025)\end{array}$ & & $\begin{array}{c}0.050^{* * *} \\
(0.008)\end{array}$ & \\
\hline \multicolumn{7}{|c|}{ Share of Active Peers at Home } \\
\hline$\times$ Conservative Decision & & $\begin{array}{c}0.289^{*} \\
(0.173)\end{array}$ & & $\begin{array}{l}0.470^{* *} \\
(0.237)\end{array}$ & & $\begin{array}{l}0.198^{* *} \\
(0.093)\end{array}$ \\
\hline$\times$ Liberal Decision & & $\begin{array}{c}-0.579 * * * \\
(0.177)\end{array}$ & & $\begin{array}{c}-1.420^{* * *} \\
(0.256)\end{array}$ & & $\begin{array}{c}-0.304^{* * *} \\
(0.095)\end{array}$ \\
\hline \multicolumn{7}{|c|}{ Active Peer Mean Years at Home } \\
\hline$\times$ Conservative Decision & & $\begin{array}{c}-0.054^{* *} \\
(0.026)\end{array}$ & & $\begin{array}{c}-0.085^{* * *} \\
(0.031)\end{array}$ & & $\begin{array}{c}-0.027^{* * *} \\
(0.009)\end{array}$ \\
\hline$\times$ Liberal Decision & & $\begin{array}{c}0.070^{* * *} \\
(0.021)\end{array}$ & & $\begin{array}{c}0.231^{* * *} \\
(0.027)\end{array}$ & & $\begin{array}{c}0.053^{* * *} \\
(0.009)\end{array}$ \\
\hline R-squared & 0.6886 & 0.6886 & 0.5853 & 0.5870 & 0.0841 & 0.0885 \\
\hline First Stage F-Statistic & 5.369 & 5.284 & 25.032 & 26.180 & 23.051 & 24.506 \\
\hline First Stage P-Value & 0.000 & 0.000 & 0.000 & 0.000 & 0.000 & 0.000 \\
\hline
\end{tabular}

All regressions include a control for the mean ideology of active peers, plus the same controls as in Model 1 in Table 3. $\mathrm{N}=110,729$ votes. ${ }^{*} \mathrm{p}<0.10,{ }^{* *} \mathrm{p}<0.05,{ }^{* * *} \mathrm{p}<0.01$

their home court. The answer is yes: We find that a percentage point increase in the proportion of home peers who issue a conservative vote in a case makes other justices 0.3 percentage points more likely to conservative. Accordingly, in cases with a single home justice, switching their vote has a 30 percentage point effect on peer votes. This effect may seem large, but it is actually smaller then the effect that Fischman (2015) finds for peer votes on circuit courts.

The final two columns consider our third measure of peer votes, the net vote direction of active peers. An additional home justice voting conservative in a case increases this variable by one-eighth. It's estimated coefficient is 1.36 or 1.07 , depending on whether we use the all home peer or active home peer instrument. So we estimate that an additional home peer justice voting conservative increases the conservative vote share of other justices by roughly $14 \%$ to $17 \%$. 
Table 8 - Structural Model of Endogenous and Exogenous Peer Effects

\begin{tabular}{lcccccc}
\hline \hline & $(1)$ & $(2)$ & $(3)$ & $(4)$ & $(5)$ & $(6)$ \\
\hline Active Peer Votes & $0.894^{* * *}$ & $0.877^{* * *}$ & & & & \\
Home Peer Votes & $(0.037)$ & $(0.041)$ & & & & \\
& & & $0.342^{* * *}$ & $0.303^{* * *}$ & & \\
Net Home Peer Votes & & & $(0.068)$ & $(0.064)$ & & \\
& & & & & $1.366^{* * *}$ & $1.071^{* * *}$ \\
& & & & & $(0.282)$ & $(0.254)$ \\
Active Peer Ideology & $-0.505^{* * *}$ & $-0.471^{* * *}$ & $1.111^{* * *}$ & $1.113^{* * *}$ & $1.095^{* * *}$ & $1.102^{* * *}$ \\
& $(0.087)$ & $(0.097)$ & $(0.310)$ & $(0.311)$ & $(0.309)$ & $(0.311)$ \\
\hline Home Peer Instruments & All & Active & All & Active & All & Active \\
First Stage F-Statistic & 5.368 & 5.285 & 24.485 & 25.878 & 20.018 & 22.020 \\
\hline \hline
\end{tabular}

All regressions include the same controls as Model 1 in Table 3. $\mathrm{N}=110,729$ votes. ${ }^{* * *} \mathrm{p}<0.01$

The structural models in Table 8 also provide estimates of exogenous peer effects, operating through mean active peer ideology. Notice that in our main model in column (1) the effect of active peer ideology is negative. But care must be taken in interpreting this result: It should be interpreted as the effect of a change in peer ideology, holding peer votes constant. This has an intuitive interpretation: holding the number of peers who vote in the conservative direction fixed, a more conservative peer groups make that vote less convincing. Conversely, the more liberal is the peer group of justices who vote conservatively, the more persuasive that vote is. ${ }^{26}$

\section{The Effect of Peer Votes on Case Outcomes}

We have provided strong evidence that peers affect votes. But if they do not change pivotal votes, and thus alter the direction of case outcomes, they are of diminished practical interest. Here we seek to to establish whether the peer effects documented above affect case outcomes in a significant way, or only affect votes in cases that are not tightly decided.

The analysis in Sections 3 and 4 considered the effect of peer votes and ideology on the votes of a single justice. But to determine whether peer effects change pivotal votes, we must estimate how the ideology and votes of a single justice affects the collective vote of his/her peers.

\footnotetext{
${ }^{26}$ In contrast, in Table 8 columns 3 to 4 , where we estimate the effects home peer votes in home court cases, the coefficients on active peer ideology are positive and roughly 1.11. This is very similar to the peer ideology effects reported for Model 1B in Section 3. Controlling for the vote share of home peers in home court cases has only a minor effect on the ideology coefficient, as justices are home rather infrequently. The same logic applies to columns 5 and 6.
} 
Letting $f(\cdot)$ represents the pertinent collective vote measure of the peer justices and $d_{j c}$ the vote of the justice whose perspective is taken, we estimate regressions of the form:

$$
f\left(\frac{1}{N-1} \sum_{i \in I_{j c}} d_{i c}\right)=\alpha_{j}+\beta_{p}^{v} \times d_{j c}+X_{c}^{\prime} \beta+\delta_{t(c)}+\varepsilon_{j c}
$$

As in Section 4, a justice's own vote is endogenous because it is jointly determined with the votes of peers. In particular, it is in part determined by unobserved case characteristics that drive all justices votes in a particular case. To deal with this endogeneity problem, we use the "home" court bias instruments. Here, the instrument is simply an indicator for whether the case is sourced from the home court of justice $j$ whose vote $d_{j c}$ is the endogenous variable in equation (4).

Using this approach, we consider the effects of a justice's own vote on two different measures of the collective peer vote $f(\cdot)$. First, we consider simply the number of conservative votes by the other eight justices (Note: In this section we restrict attention to cases with a full panel of justices). This specification allows us to ascertain the average magnitude of peer vote effects at the case level, which is of interest in itself, but it sheds no light on whether peer effects are pivotal.

Second and more importantly, in order to ascertain whether peer effects change pivotal votes, we define a case outcome as potentially conservative if, not counting justice $j$ 's own vote, enough others (i.e., at least four) vote in the conservative direction, so a conservative outcome is possible. We then define $f()$ as a 1/0 indicator for whether a case has a conservation outcome potential. Considering the potential outcome, rather than the actual, enables us to estimate the effect of a justice's own vote on the decision's direction, excluding the mechanical effect of his/her own vote. We can also define $f()$ as a $1 / 0$ indicator for whether a case has a potentially liberal outcome. ${ }^{27}$

For simplicity we restrict the sample to cases with either zero or one justice at home. In cases with a home justice, full weight is given to the home justice's observation (such that the dependent variable is based only on the votes of the away justices). In cases where all justices are away each is given equal (1/9) weight. This means that in total, each case is weighted equally, and there is no arbitrariness in which justices are included in the dependent or independent variables.

\footnotetext{
${ }^{27}$ Thus it is possible that a case can have both conservative and liberal potential from the perspective of some justice when they are voting, with their own vote deciding the actual decision direction.
} 
A few details of the specification are worth noting. First, differences in the voting propensities of different natural Courts (i.e., cohorts of justices) are captured by term fixed effects. ${ }^{28}$ However, the dependent variable is still mechanically affected by the ideology of the individual justice whose perspective is taken. This is addressed by the inclusion of justice fixed effects. ${ }^{29}$ Finally, $X_{c}$ includes lower court decision direction, legal issue area and circuit court fixed effects.

The results for these analyses are shown in the first column of Table 9, with each row corresponding to one of the three alternative outcome measures. The first row presents our result for total conservative votes by the eight peer justices. Our estimates imply that a single (implicitly home) justice switching their vote changes the net votes of their (away) peers by approximately 2.8 votes collectively. While this effect may seem large, we think it is plausible. The cases the Court hears tend to be difficult, and the panel consists of nine justices with diverse ideology and expertise. Thus it seems likely that at least a few justices are marginal on many cases, and hence persuadable by a conservative colleague who votes in the liberal direction, or vice versa, particularly if that colleague is perceived as having special expertise in the case.

Moreover, our estimate is consistent with the large effect of peer votes estimated by Fischman (2015) for federal circuit courts, and consistent with the large effects we found in our individuallevel analysis in Section 4. This result highlights the empirical importance of peer effects; the indirect effect of a home justice's vote on the total vote outcome through the votes of their peers is larger than the direct mechanical effect of the justice's own vote.

Table 9 - Peer Vote Effects on Verdict Direction Outcomes IV

\begin{tabular}{lccc}
\hline \hline & $(1)$ & $(2)$ & $(3)$ \\
& Conservative & Conservative & Liberal \\
& Peer Votes & Potential & Potential \\
\hline Vote Direction & $2.792^{* * *}$ & $0.362^{* * *}$ & $-0.323^{* *}$ \\
& $(0.684)$ & $(0.128)$ & $(0.133)$ \\
\hline First Stage F-Statistic & 11.776 & 11.776 & 11.776 \\
\hline \hline
\end{tabular}

All regressions restricted to cases with a full panel (9) of justices and $0-1$ home justices. $\mathrm{N}=68,800$ votes. ${ }^{* *} \mathrm{p}<0.05,{ }^{* * *} \mathrm{p}<0.01$.

\footnotetext{
${ }^{28}$ Recall that almost all of the within-year variation in justice cohort is due to absences, which are excluded since only full panel cases are considered here.

${ }^{29}$ Note that explicitly controlling for excluded justice's estimated ideology to capture justice peer ideology effects is redundant as this is perfectly collinear with the justice fixed effects.
} 
Rows 2 and 3 report the results for the conservative and liberal potential outcome measures. We again find positive peer effects. Our estimates imply that a home justice switching their vote from liberal to conservative increases the share of cases with a conservative outcome potential ${ }^{30}$ by 36 percentage points, and reduces the share with liberal potential by 32 percentage points. This implies that home justice votes do have a large impact on case majorities.

These results imply that peer effects do not merely arise in one-sided cases. The finding that peer effects can affect case outcomes suggests that the peer effects we find cannot be purely due to dissent aversion. We discuss some alternative explanations in the next section.

\section{Discussion and Conclusion}

We have presented strong evidence for the existence of peer effects on the US Supreme Court. Both the ideology and voting behavior of a justice exert an influence on the votes of other justices. Moreover, our estimates imply that these peer effects can be pivotal and thus affect case outcomes. The magnitudes of the peer effects we find are substantial.

This raises the question of why these effects exist and what drives them. As we mentioned in the introduction, a variety of explanations have been offered in the context of lower courts, including: deliberation, group polarization, aversion to dissent, or deference to expertise. We have shown, by virtue of the fact that peer effects can cause a change in outcome, that dissent aversion (not wanting be an outlier justice on a case) cannot be the whole story.

Having said that, it is challenging to provide compelling evidence distinguishing between the other channels: It is not easy to distinguish between justices persuading each other, being deferential to each other on areas of expertise, or even some form of horse trading. We can, however, get some sense of whether Posner (2008)'s deference effect is at work. Under that hypothesis, roughly put, justices defer to other justices who have expertise in a certain area of law. But deference is less for highly politicized issues. As Posner puts it: "The hotter the issue (such as abortion, which nowadays is much hotter than, say, criminal sentencing), the greater the explanatory power of the political variable."

\footnotetext{
${ }^{30}$ For example, shifting the vote of other justices from 3-5 or less to 4-4 or more.
} 
In the following table, we estimate our peer effect coefficient (including justice by issue area and term by issue area fixed effects) separately for the 11 issue areas. To facilitate precise estimates, we estimate regressions of a justices own vote on the mean peer vote (along with the same control variables used previously in Section 4), but with ideology excluded. That is, we assume there are only endogenous peer effects. Identification for each issue area comes from using the mean active justice ideology estimates in that issue area as instruments for the mean vote of peers. A first thing to note is that the 11 issue areas are fairly coarse categories that typically include some "hot" issues and some less controversial ones. Second, some of the first stage F-statistics indicate weak instrument problems, and some of the standard errors are large (the Privacy and Unions coefficients, for instance, are almost completely uninformative).

Notwithstanding these issues, it is noteworthy that, relative to the average coefficient of about 0.6, the issue areas with stronger peer effects include: Attorneys, Economic Activity, Judicial Power and Federal Taxation, all of which are arguably on the "cooler" end of the political spectrum. Conversely, First Amendment, Civil Rights and Due Process have lower-than-average coefficients, and the areas are arguably on the "hotter" end of the political spectrum.

Table 10 - Peer Effects by Issue Area - Justice by Issue Area, Term by Issue Area FE

\begin{tabular}{lcccc}
\hline \hline & Coefficient & Standard Error & First Stage F-Statistic & Observations \\
\hline Unions & -0.109 & 2.594 & 0.179 & 4387 \\
Civil Rights & 0.346 & 0.350 & 3.370 & 18435 \\
Due Process & 0.442 & 0.535 & 1.427 & 4975 \\
First Amendment & $0.547^{* * *}$ & 0.162 & 8.674 & 9895 \\
Criminal Procedure & $0.601^{* * *}$ & 0.077 & 29.143 & 22549 \\
Economic Activity & $0.674^{* * *}$ & 0.105 & 11.508 & 21447 \\
Attorneys & $0.724^{* * *}$ & 0.196 & 3.239 & 1122 \\
Federal Taxation & $0.760^{* * *}$ & 0.145 & 4.123 & 3415 \\
Judicial Power & $0.806^{* * *}$ & 0.067 & 10.020 & 17041 \\
Federalism & $0.853^{* * *}$ & 0.092 & 3.685 & 5805 \\
Privacy & 2.096 & 2.376 & 0.226 & 1483 \\
\hline \hline
\end{tabular}

These specifications are analogous to those in Table 8, except separate by issue area and excluding active peer ideology. ${ }^{*} \mathrm{p}<0.10,{ }^{* *} \mathrm{p}<0.05,{ }^{* * *} \mathrm{p}<0.01$

It is worth noting however, that the "hot button" issue effect that Posner conjectures, and that we provide some evidence for, could still operate in the absence of deference to expertise. It could simply be that on "hot button" cases justices decide ideologically, and on other cases they 
are more persuadable by their colleagues.

Our estimates of peer effects speak to the broader issue of the optimal strategy for a president nominating a justice. This requires balancing the proximity of the justice's ideology to that of the president, with the effect the justice will have on their peers. An implication is that optimal nominations are "court specific" in the sense that they depend on the existing justices, as well as presidential preferences. ${ }^{31}$ As home court justices are so influential, an intriguing implication of our results is that-for given ideology-a President should prefer to appoint a circuit court judge. As noted by Epstein et al. (2009), this has been a strong recent trend.

The magnitude of the peer effects that we estimate imply that the indirect effect of a justice's vote on the outcome through the votes of their peers is larger than the direct mechanical effect of the justice's own vote. The replacement of a particularly liberal or conservative justice is especially consequential in that it has the potential to have a large impact on case outcomes.

To highlight the magnitude and importance of the effects we estimate, one can consider the implied impact of replacing retired justice Anthony Kennedy with Justice Brett Kavanaugh. Using "Judicial Common Space" (Epstein et al. (2007)) measures of ideology plus the fact that Kavanaugh was nominated by a Republican President, we use the set of justices with JCS scores and our own ideology scores to produce an appropriately scaled estimate of Kavanaugh's ideology. Using our peer effect estimates we estimate that replacing Justice Kennedy with Justice Kavanaugh would have made each other justice only $0.3 \%$ more likely to vote conservative on a given case (the effect being muted here because Kavanaugh has a forecast ideology very similar to Kennedy's point estimate). In contrast, if Merrick Garland had succeeded Justice Scalia, we estimate that would have made each other justice $5.1 \%$ more likely to vote liberal on a given case.

\footnotetext{
${ }^{31}$ Here it is important note that optimal appointment may depend on heterogeneity or nonlinearity in peer effects. While our estimates are of the average proportional treatment effect of being exposed to a change in peer ideology or voting disposition, it is plausible that the ability of one justice to convince another diminishes as they become ideologically distant. Convincingly identifying these nonlinearities is difficult, and thus left for future work.
} 


\section{Appendices}

\section{A Nonlinear Least Squares: Iterative Estimation Method}

If the peer ideology variable (which we denote by $\bar{\alpha}_{-j c}$ ) were observed, we could estimate the linear probability model in equation (1) by running the fixed effects regression:

$$
d_{j c}=\alpha_{j}+\beta_{p} \bar{\alpha}_{-j c}+X_{c}^{\prime} \beta+\delta_{t(c)}+\epsilon_{j c}
$$

where $\alpha_{j}$ is the fixed effect that captures ideology of justice $j$ and $\bar{\alpha}_{-j c}=\frac{1}{\left|I_{c j}\right|} \sum_{i \in I_{c j}} \alpha_{i}$ is the mean ideology of peers active in case $c$. However, as $\bar{\alpha}_{-j c}$ is unobserved we instead implement the nonlinear least squares (NLLS) estimator:

$$
\min _{\alpha, \beta, \delta} \sum_{c, j}\left[d_{j c}-\alpha_{j}-\beta_{p} \bar{\alpha}_{-j c}-X_{c}^{\prime} \beta-\delta_{t(c)}\right]^{2}
$$

The computational problem is now function minimization over a large number of fixed effects and other parameters. We now discuss alternative solutions to that problem.

Arcidiacono et al. (2012) consider essentially the same problem in a different context (i.e., students whose performance in classes is determined both by their own fixed effect, which measures latent ability, and the average fixed effect of the peer students with whom they are grouped). They propose an iterative procedure for finding the minimum of the NLLS objective function that consists of two steps: (i) starting from a guess (or prior iteration estimate) of the fixed effects vector $\alpha$, estimate the other model parameters by OLS, (ii) conditional on the OLS estimate of the other model parameters, solve a fixed point problem to obtain the estimate of the $\alpha$ vector that minimizes the NLLS objective function. ${ }^{32}$ Iterate between steps (i) and (ii) until convergence.

We propose an alternative search algorithm that is much simpler to implement in our case, and that converges very quickly to a solution. They key idea of our algorithm is that, conditional on (hypothetical) known values of the peer effect variable $\left(\bar{\alpha}_{-j c}\right)$, the parameter vector that solves the

\footnotetext{
${ }^{32}$ By setting the vector of derivatives of the NLLS objective function with respect to the fixed effects equal to zero, one obtains the set of equations that is solved in the fixed point problem.
} 
NLLS minimization problem in (6) satisfies the OLS normal equations - which of course are linear in parameters and can be solved by linear regression. So our idea is to start with a guess for the vector of peer effect variables $\left(\bar{\alpha}_{-j c}\right)$, and then solve for the parameter vector $(\alpha, \beta, \delta)$ by OLS. Then we refine our guess of the peer effects variables until the guess coincides with the fixed effects we estimate by OLS - that is, until $\bar{\alpha}_{-j c}=\frac{1}{\left|I_{c j}\right|} \sum_{i \in I_{c j}} \alpha_{i} \forall j, c$. At which point we have a solution of the NLLS minimization problem in (6).

In order to explain the algorithm we first set some notation: Let $\bar{\alpha}_{-j c}^{t}$ denote the value of the peer effect variable assumed in iteration $t$, and let $\alpha^{t}$ denote the vector of fixed effects estimated by linear regression on iteration $t$, taking the peer measures $\bar{\alpha}_{-j c}^{t}$ as given. At the start of iteration $t+1$, update the peer measures as $\bar{\alpha}_{-j c}^{t+1}=\frac{1}{\left|I_{c j}\right|} \sum_{i \in I_{c j}} \alpha_{i}^{t}$.

The algorithm is as follows: In the first iteration, estimate the linear probability model in equation (5) by fixed effects regression, assuming that $\bar{\alpha}_{-j c}^{1}=0$. That is, the unknown peer effect variable is initially set to zero. In the second iteration, construct the peer effect variable using the estimated fixed effects from the first iteration, $\bar{\alpha}_{-j c}^{2}=\frac{1}{\left|I_{c j}\right|} \sum_{i \in I_{c j}} \alpha_{i}^{1}$, and re-estimate the linear probability model in equation (5) by fixed effects regression. In each subsequent iteration, construct $\bar{\alpha}_{-j c}^{t}$ using the fixed effects $\alpha_{i}^{t-1}$ estimated from the prior iteration, and and re-estimate the linear probability model in equation (5) by fixed effects regression to obtain new estimates of the fixed effects $\alpha_{i}^{t}$. Repeat until the estimates converge to a desired degree of tolerance.

At convergence, the estimates provide a (local) solution for the minimization problem in equation (6) by construction. ${ }^{33}$ This is because at each iteration, all estimated parameters satisfy the OLS normal equations conditional on the assumed values of the peer effect terms (based on the estimated fixed effects from the prior iteration). Once convergence is achieved, such that the estimates of the fixed effects are constant from one iteration to the next (to the assumed tolerance), the assumed peer effect terms are consistent with the estimated fixed effects from the current iteration. That is, $\bar{\alpha}_{-j c}^{T}=\frac{1}{\left|I_{c j}\right|} \sum_{i \in I_{c j}} \alpha_{i}^{T}{ }^{34}$ So at convergence the OLS normal equations are satisfied conditional on internally consistent values for the peer effect variables.

\footnotetext{
${ }^{33}$ Nonlinear search algorithms do not generally provide global solutions, unless one can prove the objective function is globally concave. In practice, we detected no problems with multiple solutions.

${ }^{34}$ Except, of course, for the arbitrarily small deviation allowed by the convergence tolerance.
} 
For the models we consider, this algorithm converges to a solution on the 3rd iteration. This occurs because our 1st iteration estimates of the fixed effects $\alpha^{1}$ generate peer variables for the 2nd iteration $\bar{\alpha}_{-j c}^{2}$ that, after a fixed effects transformation, only differ from the "correct" peer effect variables by a scale factor. We explain why in Appendix A.1. Our second iteration generates estimates of the fixed effects $\alpha^{2}$ that satisfy the OLS normal equations conditional on these scaled $\bar{\alpha}_{-j c}^{2}$. But crucially, merely rescaling the $\bar{\alpha}_{-j c}^{2}$ does not alter the linear regression estimates of $\alpha^{2}$. Hence, the fixed effects $\alpha^{2}$ will continue to satisfy the OLS normal equations conditional on any re-scaling of the the peer effects variables. Thus, we already obtain on iteration 2 the vector of fixed

effects $\alpha$ that solve equation (6). Thus, on iteration 3 we will already have $\bar{\alpha}_{-j c}^{3}=\frac{1}{\left|I_{c j}\right|} \sum_{i \in I_{c j}} \alpha_{i}^{3}$. So the iteration 3 estimates of the parameter vector $(\alpha, \beta, \delta)$ will also solve equation (6).

\section{A.1 Properties of the Second Iteration Estimates}

The first iteration of our algorithm estimates justice ideology fixed effects under the assumption of no peer effects. Hence, our first iteration justice ideology measures are contaminated by the peer effects coming from other justices. This in turn causes our peer ideology measures $\left(\bar{\alpha}_{-j c}\right)$ to be contaminated by a justice's own ideology. However, this contamination is washed out by the fixed effects in our second iteration regression. As a result, our second iteration (i) generates consistent estimates of justice ideologies that solve the NLLS minimization problem in equation (6), and (ii) gives a consistent estimate of $\beta_{p}\left(\frac{N-1}{N-1-\beta_{p}}\right)$, the true peer coefficient $\beta_{p}$ times a scale factor that depends on the number of justices $N$. We now show these results formally.

To clarify the key idea that drives the results, first consider a simplified version of equation (1) where votes are determined by the linear probability model:

$$
d_{j c}=\alpha_{j}+\beta \bar{\alpha}_{-j c}+\varepsilon_{j c}
$$

and a simple data generating process where court composition is unchanged during the tenure of each justice $j$, and where the full panel of judges hears all cases. Then $\bar{\alpha}_{-j c}$ is a constant, which we denote by $\bar{\alpha}_{-j}$. So if we estimate the (mis-specified) equation $d_{j c}=\alpha_{j}^{p}+\xi_{j c}$ that ignores peer effects, we will obtain, in large samples, the proxy ideology measures $\alpha_{j}^{p}=\alpha_{j}+\beta \bar{\alpha}_{-j}$. Thus, our initial ideology measures, obtained from a model that ignores peer effects, are contaminated by those peer effects. Suppose we nevertheless use them to construct an initial estimate of the peer 
ideology variable, which we denote by $\bar{\alpha}_{-j}^{p}$ :

$$
\begin{aligned}
\bar{\alpha}_{-j}^{p}= & \frac{1}{N-1} \sum_{k \neq j} \alpha_{k}^{p}=\frac{1}{N-1} \sum_{k \neq j}\left(\alpha_{k}+\beta \bar{\alpha}_{-k}\right) \\
= & \left(\frac{1}{N-1} \sum_{k \neq j} \alpha_{k}\right)+\beta\left(\frac{1}{N-1} \sum_{k \neq j} \bar{\alpha}_{-k}\right) \\
= & \bar{\alpha}_{-j}+\frac{\beta}{N-1}\left(\frac { 1 } { N - 1 } \left\{\left(\alpha_{2}+\ldots+\alpha_{j}+\ldots+\alpha_{N}\right)+\left(\alpha_{1}+\alpha_{3}+\ldots+\alpha_{j}+\ldots+\alpha_{N}\right)+\ldots\right.\right. \\
& \left.\left.\left.+\left(\alpha_{1}+\ldots+\alpha_{j}+\ldots \alpha_{N-2}\right)\right\}\right)\right) \\
= & (1+\beta) \bar{\alpha}_{-j}+\frac{\beta}{N-1}\left(\alpha_{j}-\bar{\alpha}_{-j}\right)=\left(1+\frac{N-2}{N-1} \beta\right) \bar{\alpha}_{-j}+\frac{\beta}{N-1} \alpha_{j} .
\end{aligned}
$$

Thus the proxy peer effect measure consists of a scaled version of the true peer variable $\bar{\alpha}_{-j}$, plus a "contamination" due to the justice's own ideology (the $\frac{\beta}{N-1} \alpha_{j}$ term).

Now consider the more realistic data generating process where justice $j$ is observed sitting on a number of different courts $g=1, \ldots, G$, each with a different (but typically overlapping) group of $N-1$ other justices who are concurrently appointed to the court. This allows the exposure of a particular justice to another to vary across cases and across justice pairs, while within a group $g$, composition of the court may still vary due to absences. The true model is now:

$$
d_{j c}=\alpha_{j}+\beta \bar{\alpha}_{-j, g}+\varepsilon_{j c}
$$

If one instead estimates $d_{j c}=\alpha_{j}^{p}+\xi_{j c}$ then, given a large number of cases alongside each peer, the Khintchine Law of Large Numbers implies that one obtains the initial ideology measures:

$$
\alpha_{j}^{p}=\alpha_{j}+\beta\left\{\pi_{1}^{j} \alpha_{1}+\pi_{2}^{j} \alpha_{2} \ldots+\pi_{n}^{j} \alpha_{n}\right\}
$$

where $\pi_{k}^{j}$ is the exposure weight of justice $j$ to justice $k$, with $\sum_{i} \pi_{i}^{j}=1$ and zero exposure to self, $\pi_{j}^{j}=0$. Let us now construct $\bar{\alpha}_{-j, c, g}^{p}$, the mean ideology that $j$ faces in a case $c$ with cohort $g$.

$$
\begin{aligned}
\bar{\alpha}_{-j, c, g}^{p} & =\frac{1}{N_{c}-1} \sum_{k \neq j} \alpha_{k}^{p} I_{k}^{c} . \\
& =\frac{1}{N_{c}-1} \sum_{k \neq j} \alpha_{k} I_{k}^{c}+\frac{\beta}{N_{c}-1} \sum_{k \neq j}\left(\pi_{1}^{k} \alpha_{1}+\pi_{2}^{k} \alpha_{2} \ldots+\pi_{j}^{k} \alpha_{j} \ldots+\pi_{n}^{k} \alpha_{n}\right) I_{k}^{c}
\end{aligned}
$$


where $I_{k}^{c}$ is an indicator for the presence of justice $k$ in a case $c$, and $N_{c}-1$ is the number of active peers in case $c$. The exposure of peers of $j$ to the ideology of $j$ can be separated out,

$$
\begin{aligned}
\bar{\alpha}_{-j, c, g}^{p} & =\frac{1}{N_{c}-1} \sum_{k \neq j} \alpha_{k} I_{k}^{c}+\frac{\beta}{N_{c}-1} \sum_{i}\left(\sum_{k \neq j} I_{k}^{c} \pi_{i}^{k}\right) \alpha_{i} \\
& =\frac{1}{N_{c}-1} \sum_{k \neq j} \alpha_{k} I_{k}^{c}+\frac{\beta}{N_{c}-1} \sum_{i \neq j}\left(\sum_{k \neq j} I_{k}^{c} \pi_{i}^{k}\right) \alpha_{i}+\frac{\beta}{N_{c}-1}\left(\sum_{k \neq j} I_{k}^{c} \pi_{j}^{k}\right) \alpha_{j} \\
& =\frac{1}{N_{c}-1}\left(\sum_{k \neq j} \alpha_{k}\left(I_{k}^{c}+\beta \sum_{i \neq j} I_{i}^{c} \pi_{k}^{i}\right)\right)+\frac{\beta}{N_{c}-1}\left(\sum_{k \neq j} I_{k}^{c} \pi_{j}^{k}\right) \alpha_{j}
\end{aligned}
$$

where the final term captures the exposure of the peers $j$ to the ideology of $j$.

Now suppose we use these contaminated ideology measures in the fixed effects regression:

$$
d_{j c g}=\gamma_{j g}+\theta \bar{\alpha}_{-j, c, g}^{p}+\omega_{j c} .
$$

where $\gamma_{j, g}$ are justice-by-group fixed effects and $\theta$ is the key estimated parameter that captures peer effects. For example, $g$ may categorize the intersection of issue area and natural court.

To implement the estimation with justice-by-group fixed effects we must de-mean the $\bar{\alpha}_{-j, c, g}^{p}$ over the $T$ cases $c$ within each group $g$ by justice $j$ pair. The mean is:

$\overline{\bar{\alpha}_{-j, c, g}^{p}}=\frac{1}{T} \sum_{c}\left(\frac{1}{N_{c}-1} \sum_{k \neq j} \alpha_{k} I_{k}^{c}\right)+\frac{1}{T} \sum_{c}\left(\frac{\beta}{N_{c}-1} \sum_{k \neq j}\left(\sum_{i \neq j} I_{i}^{c} \pi_{k}^{i}\right) \alpha_{k}\right)+\frac{1}{T} \sum_{c} \frac{\beta}{N_{c}-1}\left(\sum_{k \neq j} I_{k}^{c} \pi_{j}^{k}\right) \alpha_{j}$

To make this tractable, assume that justice absences are independent and equally likely within $g$. Then each justice $k$ is equally exposed to each other justice $\left(\pi_{i}^{k}=\frac{1}{N-1} \forall k \neq i\right)$. and we have:

$$
\begin{aligned}
\bar{\alpha}_{-j, c, g}^{p} & =\frac{1}{N_{c}-1} \sum_{k \neq j} \alpha_{k} I_{k}^{c}+\frac{1}{N_{c}-1} \sum_{k \neq j} \alpha_{k}\left(\beta \frac{N_{c}-1-I_{k}^{c}}{N-1}\right)+\frac{\beta}{N_{c}-1}\left(\frac{N_{c}-1}{N-1}\right) \alpha_{j} \\
& =\frac{1}{N_{c}-1} \sum_{k \neq j} \alpha_{k} I_{k}^{c}+\frac{\beta}{N-1} \sum_{k \neq j} \alpha_{k}-\frac{\beta}{N-1}\left(\frac{1}{N_{c}-1} \sum_{k \neq j} \alpha_{k} I_{k}^{c}\right)+\frac{\beta}{N-1} \alpha_{j} \\
& =\left(1-\frac{\beta}{N-1}\right) \bar{\alpha}_{-j, c, g}+\beta \overline{\alpha_{-j, g}}+\frac{\beta}{N-1} \alpha_{j}
\end{aligned}
$$


Averaging over cases we obtain:

$$
\overline{\bar{\alpha}_{-j, c, g}^{p}}=\left(1-\frac{\beta}{N-1}\right) \overline{\bar{\alpha}_{-j, c, g}}+\beta \overline{\alpha_{-j, g}}+\frac{\beta}{N-1} \alpha_{j}
$$

Observe that the $\alpha_{j}$ term collapses to $\frac{\beta}{N-1} \alpha_{j}$, which is constant across cases within $g$, and thus drops out upon demeaning. It follows that:

$$
\bar{\alpha}_{-j, c, g}^{p}-\overline{\bar{\alpha}_{-j, c, g}^{p}}=\left(1-\frac{\beta}{N-1}\right)\left(\bar{\alpha}_{-j, c, g}-\overline{\bar{\alpha}}_{-j, c, g}\right)
$$

Observe that the justice fixed effects $\alpha_{j}$ drop out of this equation as claimed.

This leaves us with the fixed-effects regression:

$$
d_{j c g}-\bar{d}_{j c g}=\theta\left(1-\frac{\beta}{N-1}\right)\left(\bar{\alpha}_{-j, c, g}-\overline{\bar{\alpha}}_{-j, c, g}\right)+\left(\omega_{j c}-\bar{\omega}_{j c}\right)
$$

where the first parenthetical term on the right is the attenuation factor and the second is the "correct" regressor. If we estimate the fixed effects model in (8) using the within transform in (10) the re-scaling of the peer variable by the attenuation factor has no impact on the estimates of the fixed effects. So the estimated fixed effects that we obtain on iteration 2 minimize the NLLS objective function in (6), and our search algorithm converges for other parameters on iteration $3 .{ }^{35} \mathrm{We}$ emphasize that this is a numerical property rather than an asymptotic result.

As for asymptotic properties, in large samples our iteration 2 estimate of $\theta$ converges to:

$$
\theta=\beta /\left(1-\frac{\beta}{N-1}\right)
$$

Therefore $\theta$ is consistent for $\beta$ if $\beta=0$, it is attenuated if $\beta<0$ and it is inflated if $\beta>0 .{ }^{36}$ In our case $N=9$, so if, e.g., $\beta=1.131$, then $\operatorname{plim}_{n \rightarrow \infty}$ of the iteration 2 estimate of $\theta$ is $\beta\left(\frac{8}{8-1.131}\right)=1.317$. So our iteration 2 estimate of the peer effect parameter is slightly inflated. Finally, consider using the estimates of equation (10) to back out iteration 2 estimates of the justice ideology fixed effects.

\footnotetext{
${ }^{35}$ Note that Model 1 in the main text contains justice and term fixed effects, while Models 2 and 3 have justice by issue and term by issue fixed effects. In each case, the fixed effects wash out the contamination of the ideology measures by a justice's own ideology on iteration 2 (as described above).

${ }^{36}$ Note that tests for the existence of peer effects will still be consistent in this case, as $\beta=0$ under the null (see Wooldridge (2010, pp.158-160), where in his notation, $G=0$ so 2SLS standard errors and test statistics are valid).
} 
In large samples we obtain consistent estimates of the true fixed effects, as the scaling of the peer variable has no impact on the estimated fixed effects. It follows that the iteration 3 estimates are consistent for all parameters. (Which is apparent as they correspond to the NLLS estimates).

\section{A.2 Extension to Nonlinear 2SLS}

We estimate the structural model of Section equation (3) by 2SLS. The first stage equation is:

$$
\frac{1}{\left|V_{j c}\right|} \sum_{i \in V_{j c}} d_{i c}=\kappa_{j}+\lambda_{p}^{i} \times \frac{1}{\left|I_{j c}\right|} \sum_{i \in I_{j c}} \alpha_{i}+\mu_{t(c)}+X_{c}^{\prime} \lambda+Z_{c}^{\prime} \gamma+\zeta_{j c}
$$

Here the dependent variable $\frac{1}{\left|V_{j c}\right|} \sum_{i \in V_{j c}} d_{i, c}$ is the endogenous peer vote measure that appears in equation (3). Our instruments $Z_{c}$ are the share of other justices at home $\frac{1}{N-1} \sum_{j \neq i} I\left(j \in I_{c}^{a}\right)$ and the average length of home court tenure per justice $\frac{1}{N-1} \sum_{j \neq i}\left(I\left(j \in I_{c}^{a}\right) \times y_{j}^{a}\right)$, as well as their interactions with the lower court decision direction. The term $\kappa_{j}$ is a fixed effect for justice $j$, while $\mu_{t(c)}$ is a fixed effect for the court term $t(c)$, and $\zeta_{j c}$ is an idiosyncratic error.

Finally, the term $\bar{\alpha}_{-j c}=\frac{1}{\left|I_{j c}\right|} \sum_{i \in I_{j c}} \alpha_{i}$ is the peer ideology measure that also appears in (3). The difficulty in estimating equations (3) and (12) is that the ideology fixed effects $\alpha$ are not known a priori. They must be constructed from the estimates of the fixed effects in (3). Hence, we estimate (3) and (12) by NLLS, augmenting (2) to include the squared residuals from (12).

We again minimize the NLLS objective using an an iterative procedure, analogous to how we estimate (5). As before, let $\bar{\alpha}_{-j c}^{t}$ denote the assumed value of the peer effect variable on iteration $t$, and let $\alpha^{t}$ denote the vector of fixed effects estimated on iteration $t$ (conditional on $\bar{\alpha}_{-j c}^{t}$ ).

The algorithm is as follows: In the first iteration, estimate the first stage equation (12) assuming that $\bar{\alpha}_{-j c}^{1}=0$. Substitute the fitted values of the peer vote variable obtained from (12) into the second stage equation (3). Then estimate (3) by fixed effects, still assuming $\bar{\alpha}_{-j c}^{1}=0$.

In the second iteration, construct the peer effect variable using the estimated fixed effects from the first iteration, $\bar{\alpha}_{-j c}^{2}=\frac{1}{\left|I_{c j}\right|} \sum_{i \in I_{c j}} \alpha_{i}^{1}$. Then re-estimate equations (12) and (3).

In each subsequent iteration, construct $\bar{\alpha}_{-j c}^{t}$ using the fixed effects $\alpha_{i}^{t-1}$ estimated from the prior iteration, and re-estimate (12) and (3). Repeat until the estimates of the fixed effects converge 
to a desired degree of tolerance. This procedure again converges in three iterations: In the first iteration we estimate the model by 2SLS ignoring the peer ideology variable. This causes the ideology fixed effects to be contaminated by the omitted peer effects, but for exactly the same reason we discussed in Appendix A.1, the fixed effects (within) transformation wipes out this contamination, up to scale. Hence, for the same reason, we obtain the ideology fixed effects that minimize the NLLS objective function on iteration 2. And this, in turn, allows us to obtain the optimized values of all other parameters on iteration 3.

\section{B Endogenous Case Selection}

As we noted in Section 2, the justices select which cases the Supreme Court will hear. It is possible that the characteristics of chosen cases may depend on justice ideology. For example, a majority coalition of justices with similar ideology may seek to enshrine is own preferences in precedent. Winning cases thus becomes an instrumental goal. The appointment of a new justice that strengthens such a coalition may make it more willing to take on cases that are more ideological (in their favored direction) and thus offer a greater prospect of setting important precedent. But these more ideological cases are also relatively hard for such a grouping to win - i.e., the more ideological a case is, the more likely is any given justice to vote in the opposite ideological direction. ${ }^{37}$ Thus, if such endogenous case selection exists, a change in the Court's ideological composition in one direction will change the distribution of cases heard, moving the average vote of continuing justices in the opposite direction. This, in turn, may bias estimates of peer effects downwards.

In order to shed light on whether this case selection mechanism is important, we consider the relationship between the mean Segal-Cover score of justices sitting on the court and case characteristics that are known to be viewed as particularly conservative or liberal. If case selection effects exist, then reviewing a larger number of conservative lower court decisions is behavior that would intuitively be consistent with a comparatively liberal Court. Figure 2 reveals a strong relationship as hypothesized, with more liberal Supreme Court cohorts (high average Segal-Cover scores) mostly reviewing conservative lower court opinions, and vice versa.

\footnotetext{
${ }^{37} \mathrm{~A}$ corollary of this idea is that if a majority wins all cases by too large a margin, they could have chosen harder targets and still been successful.
} 


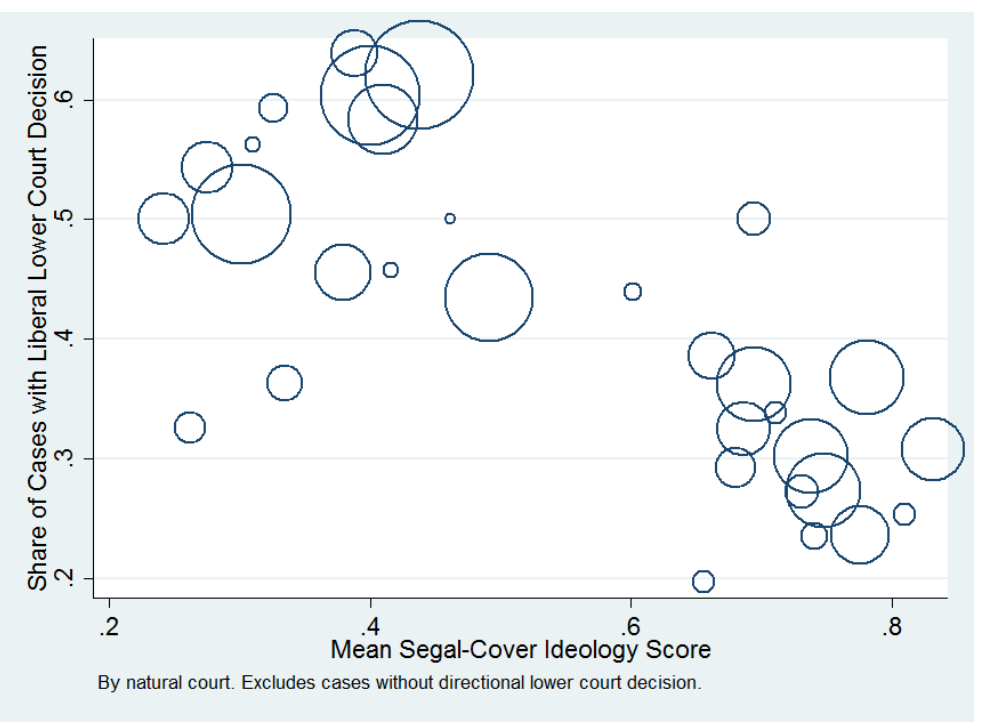

Figure 2 - Endogenous Case Ideology Selection

This analysis reveals an important reason to control for term fixed effects in the models in Sections 3.5 and 3.5.1. To the extent that case selection is governed by the justices jointly, case selection effects will be common (at least by issue area) within a natural court. Term dummies capture this effect, so the peer effect coefficients we report in Tables 4 and 5 would not be biased by endogenous case selection.

\section{Conservative Vote Share}

Figure 3 shows that the conservative vote share has varied substantially over time.

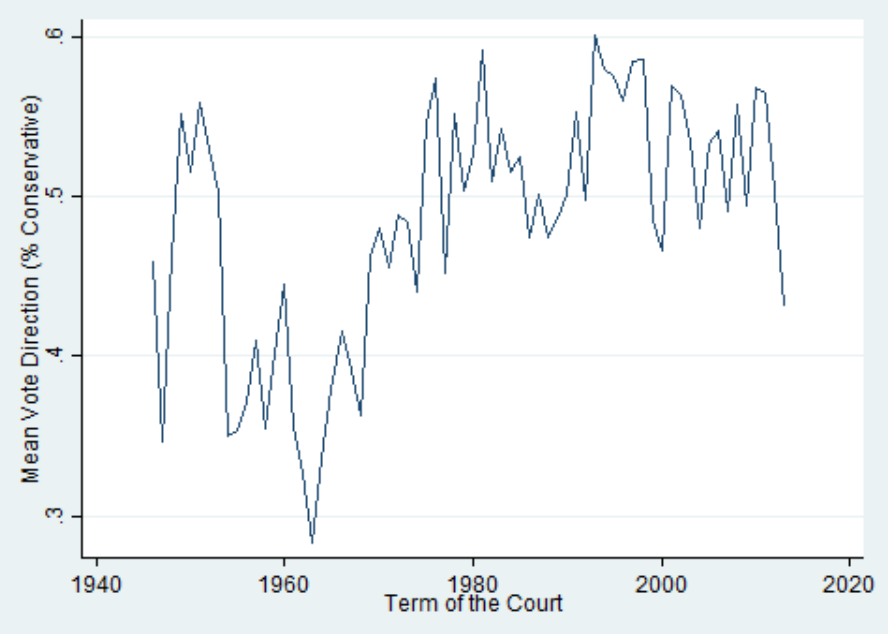

Figure 3 - Evolution of Conservative Vote Share by Term 


\section{References}

Arcidiacono, Peter, Gigi Foster, Natalie Goodpaster, and Josh Kinsler, "Estimating spillovers using panel data, with an application to the classroom," Quantitative Economics, 2012, pp. 421470 .

Bailey, Michael A. and Forrest Maltzman, The Constrained Court : Law, Politics, and the Decisions Justices Make., Princeton University Press, 2011.

Black, Ryan and Lee Epstein, "Recusals and an Equally Divided Supreme Court," The Journal of Appellate Practice and Process, 2005, 7 (1), 75-100.

Boyd, Christina L., Lee Epstein, and Andrew D. Martin, "Untangling the Causal Effects of Sex on Judging," American Journal of Political Science, 2010, 54 (2), 389 - 411.

Carrubba, Clifford J. and Christopher Zorn, "Executive Discretion, Judicial Decision Making, and Separation of Powers in the United States," The Journal of Politics, 2010, 72 (3), 812-824.

Coleman, James S., Ernest Q. Campbell, Carol J. Hobson, James McPartland, Alexander M. Mood, Frederic D. Weinfeld, and Robert L. York, Equality of Educational Opportunity, Washington D.C.: U.S. Government Printing Office, 1966.

Epstein, Lee and Tonja Jacobi, "Super Medians," Stanford Law Review, 2008, 61 (37), 37-100.

- , Andrew D. Martin, Jeffrey A. Segal, and Chad Westerland, "The Judicial Common Space," Journal of Law, Economics and Organization, 2007, 23 (2), 303-325.

_, , , Kevin M. Quinn, and Jeffrey A. Segal, "Circuit Effects: How the Norm of Federal Judicial Experience Biases the Supreme Court," University of Pennsylvania Law Review, 2009, 157, 833880.

_ , Thomas G. Walker, Nancy Staudt, Scott Hendrickson, and Jason Roberts, "The U.S. Supreme Court Justices Database," 2013. Available at: http://epstein.wustl.edu/research/ justicesdata.html.

_, William M. Landes, and Richard A. Posner, "Why (And When) Judges Dissent: A Theoretical And Empirical Analysis," Journal of Legal Analysis, 2011, 3 (1), 101-137.

Fischman, Joshua B., "Interpreting Circuit Court Voting Patterns: A Social Interactions Framework," Journal of Law, Economics and Organization, 2015, 31 (4), 808-842.

Greenhouse, Linda, Becoming Justice Blackmun: Harry Blackmun's Supreme Court Journey, Macmillan, 2007.

Hume, Robert J., "Deciding Not to Decide: The Politics of Recusals on the U.S. Supreme Court," Law and Society Review, 2014, 48 (3), 621-655. 
Manski, Charles F., "Identification of Endogenous Social Effects: The Reflection Problem," Review of Economic Studies, 1993, 60 (531-542).

_ , "Economic Analysis of Social Interaction," Journal of Economic Perspectives, 2000, 14 (115-136).

Martin, Andrew D. and Kevin M. Quinn, "Dynamic Ideal Point Estimation via Markov Chain Monte Carlo for the U.S. Supreme Court, 1953-1999," Political Analysis, 2002, 10 (2) (2), 134-153.

_, , , and Lee Epstein, "The Median Justice on the United States Supreme Court," North Carolina Law Review, 2005, pp. 1275-1322.

Miles, Thomas J. and Cass R. Sunstein, "Do Judges Make Regulatory Policy? An Empirical Investigation of Chevron," University of Chicago Law Review, 2006, 73 (823-882).

Moffitt, Robert A., "Policy interventions, low-level equilibria, and social interactions," in S. Durlauf and H.P. Young, eds., Social Dynamics, Cambirdge, MA: MIT Press, 2001, pp. 45-82.

Peresie, Jennifer L., "Female Judges Matter: Gender and Collegial Decision Making in the Federal Appelate Courts," Yale Law Journal, 2005, 114, 1759-1790.

Posner, Richard A., How Judges Think, Cambridge, MA: Harvard University Press, 2008.

Revesz, Richard L., "Environmental Regulation, Ideology, and the D.C.Circuit," Virginia Law Review, 1997, 83, 1717-1772.

Segal, Jeffrey A. and Albert D. Cover, "Ideological Values and the Votes of U.S. Supreme Court Justices," American Political Science Review., 1989, 83 (2), 557-565.

Spaeth, Harold J. and Lee Epstein, “Supreme Court Database, version 2014," 2014. Available at: http: //supremecourtdatabase.org.

Wooldridge, J.M., Econometric Analysis of Cross Section and Panel Data, MIT Press, 2010. 